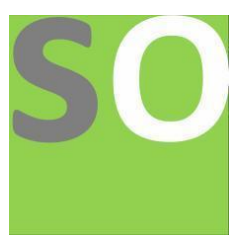

Article title: The Effect of Food and Energy Security on Political Stability

Authors: Sassi Mohamed Taher[1]

Affiliations: Master of Science MSc[1]

Orcid ids: 0000-0003-1027-8308[1]

Contact e-mail: sassimohamedtaher@gmail.com

License information: This work has been published open access under Creative Commons Attribution License http://creativecommons.org/licenses/by/4.0/, which permits unrestricted use, distribution, and reproduction in any medium, provided the original work is properly cited. Conditions, terms of use and publishing policy can be found at https://www.scienceopen.com/.

Preprint statement: This article is a preprint and has not been peer-reviewed, under consideration and submitted to ScienceOpen Preprints for open peer review.

DOI: 10.14293/S2199-1006.1.SOR-.PPIR88T.v1

Preprint first posted online: 31 May 2020

Keywords: Political Stability, Food Security, Energy Security, Fixed Effect Model 


\title{
The Effect of Food and Energy Security on Political Stability
}

\author{
Mohamed Taher Sassi
}

Philipps University Marburg

Faculty of Business Administration and Economics

Email: sassimohamedtaher@gmail.com 


\section{Table of contents}

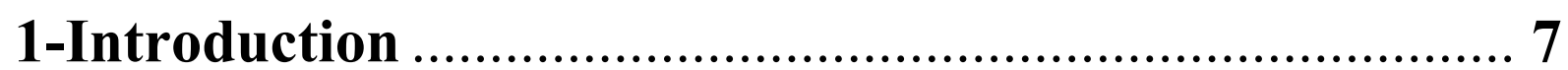

2- Review of Literature................................................ 10

2.1. Review of theoretical literature ................................ 10

2.1.1 Energy Security .................................................. 10

2.1.2 Food Security .......................................................... 14

2.1.3 Political Stability ................................................. 17

2.2. Review of empirical literature .................................... 20

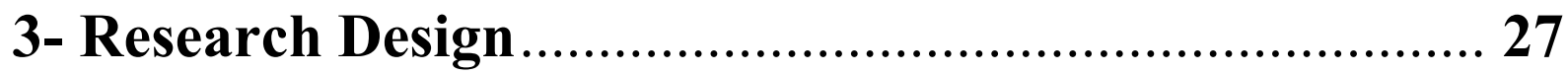

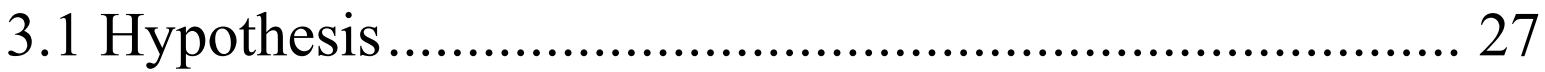

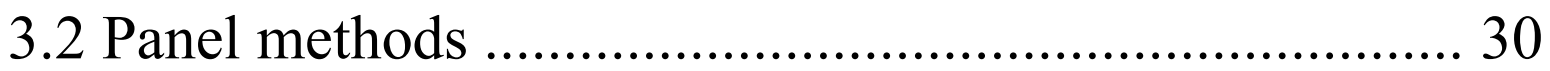

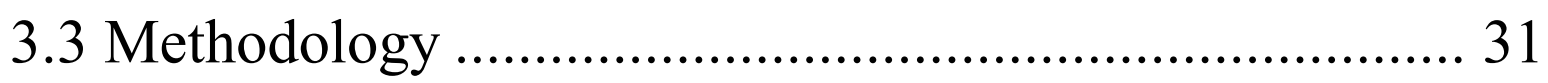

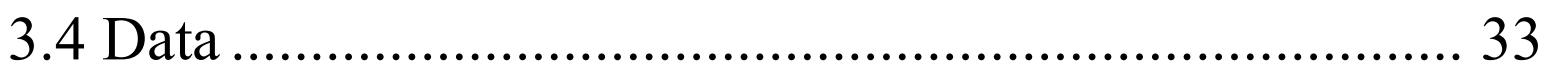

3.4.1 Independent variables........................................... 33

3.4.2 Dependent variable .............................................. 39

3.5 Global Peace Index.................................................. 40

4- Results and Discussion ................................................ 44

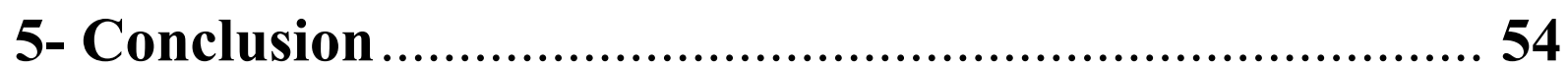

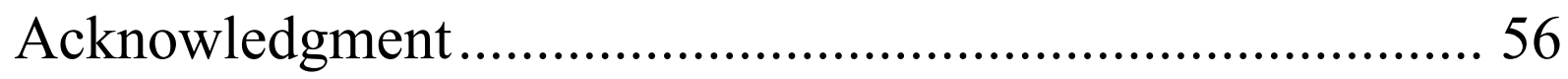

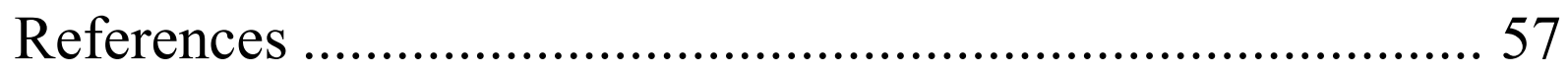

Appendix A: Additional Figures and Tables......................... 62

Appendix B: Declaration in Lieu of an Oath ....................... 66 


\section{List of Figures}

Figure 1: Annual Imported Crude Oil Price ...................................... 10

Figure 2: Annual World Food Price Indices .................................... 16

Figure 3: The new tested variables...............................................25

Figure 4: Average Food Deficit worldwide sample .........................33

Figure 5: Average Energy imports worldwide sample .....................35

Figure 6: Global Peace Index worldwide sample.............................39

Figure 7: World map of global peace ranking.................................41

Figure 8.a: Marginal effects of food deficit ....................................52

Figure 8.b: Marginal effects of food deficit.......................46

Figure 9: Relationship between average FD and GPI index (2008-

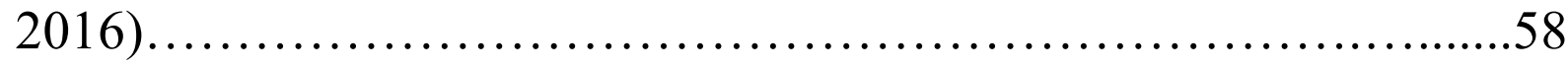

Figure 10: relationship between average RL index and GPI (20082016) 


\section{List of Tables}

Table 1: Worst countries in GPI ranking............................................ 19

Table 2: Explanatory Variables and Their Expected Signs .................29

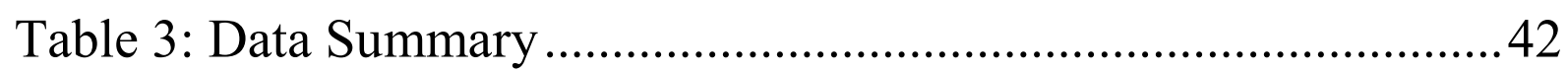

Table 4.a: Regression results of fixed effect Model (part1) ................44

Table 4.b: Regression results of fixed effect Model (part2).............38

Table 5: Last Regression results of fixed effect Model ........................48

Table 6: Average marginal effect of food deficit................................51

Table 7: Detailed Data Description ......................................................62

Table 8: Correlation Matrix of Used Variables......................................63

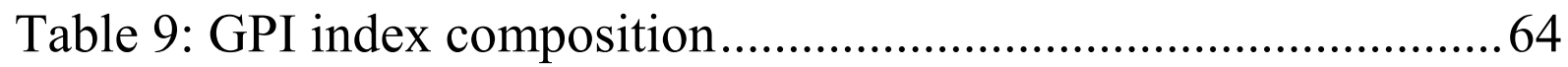




\section{List of Abbreviations}

FAO Food and Agriculture Organization

ES Energy Security

FS Food Security

PS Political Stability

OPEC Organization of the Petroleum Exporting Countries

IEA International Energy Agency

US United States of America

WB World Bank

MDG Millennium Development Goals

VAR Vector Autoregression Model

MENA Middle East and North Africa

WGI World Governance Indicators

PRS Political Risk Services

GMM Generalized Method of Moments model

IEP Institute for Economics and Peace

GPI Global Peace Index

ARDL Autoregressive Distributed Lag

FDI Foreign Direct Investment

OLS Ordinary Least Squares

FE Fixed Effect

HT Hausman Test

LM Lagrangian Multiplier Test

GDP Gross Domestic Product 
OECD Organization for Economic Co-operation and Development

ILOSTAT International Labor Organization Statistics

EI Energy Imports

Uemp Unemployment

TNR Total Natural Resource

FER Fertility Rate

FD Food Deficit

AR_land Arable Land

CC Control of Corruption

STATA Statistics and Data Software

$\mathrm{CO}_{2}$ Carbon Dioxide

RE Random Effect 


\title{
The Effect of Food and Energy Security on Political Stability
}

\author{
By: Mohamed Taher Sassi \\ Philipps-Universität Marburg, School of Business and Economics \\ Master of Science Economics \& Institutions
}

\begin{abstract}
Since both food security and energy security are countries' strategic objective, this study typically advocates a deep understanding of the concept of political stability to incorporate food and energy security as a new pillar of conflict management based on an empirical understanding of the nexus and its effect. We used food deficit as proxy for food security and energy imports for energy security from the World Bank database. Using the panel fixed effect method on data for more than 150 countries from 2008 to 2016, we identified a highly significant positive effect of economic growth, tourism and high institutional quality on stability. Destabilizing factors were also detected such as corruption and arable land scarcity. The negative effect of food insecurity was illustrated after the introduction of the squared term of food deficit. Energy imports also have a destabilizing effect. These results for the effect of food and energy security effect holds robust to various control of other determinants in our regression. This study calls for more attention to the energy and food strategy within a country. Keeping peace and stability in the world will require development effort and technological exchange between countries in terms of food strategy and renewable energy plans. These measures will boost economic growth and improve the quality of institutions which will help fighting corruption.
\end{abstract}

Key words: Political Stability, Food Security, Energy Security, Fixed Effect, Panel Data. 


\section{1-Introduction}

Suffering, mutilation and death of human beings are the most obvious and important effects of all conflicts, as well as natural disasters. Yet, material losses are also important because they reduce the livelihood and recovery capacities of conflict survivors. Moreover, in many cases, the indirect effects of conflict cause more deaths than direct violence. It has been found that generally the indirect costs of war are greater than its direct costs and persist long after the end of the conflict. Instability and conflict affect many economic sectors such as reducing foreign exchange earnings, which can have serious consequences for development and food security. Indeed, global population growth combined with the effects of climate change on agriculture pose the risk of a Malthusian trap to humanity that can only be avoided by a more efficient and sustainable production system. Energy security policies and climate policies are often considered as two sides of the same coin, their objectives being at least complementary, if not identical.

In the year of 2000 the Millennium Summit of the United Nations established eight international development goals. At that time the strategic plan was to work on realizing these objectives by the year 2015. The determined goals were fighting poverty, improving education, promoting gender equality, improving the health situation of people in the world, ensuring sustainability and especially encouraging strong worldwide partnership for development (MDGs, UN 2015). In order to assess this MDGs 2015 plan and help understanding why some outlined objectives are still not reached in a satisfactory manner, this study will contribute to the path of scientific recommendation to policy makers and strategic planners. To help achieving these goals in the future there is a need for understanding how stability could be realized.

Over decades food and energy have been vital and essential elements for the well-being of all humanity. Their importance depends on two dimensions which are quantity and quality. The quantity could be reflected by the availability of these resources and the quality part by its effects (environmental effects, like CO2 emission for energy and the nutritional aspect of food and its effects on the human body). These two relevant components could play a big role in shaping the relationship between people and even countries. Derived from the Latin word "confligere" which means strike or conflict, food and energy might be one of the causes of conflict. 
Kimbrough et al. (2017) in their review paper about war and conflict from an economic perspective have defined conflict as follows: "A conflict is a situation in which agents choose inputs that are (i) costly both to themselves and relative to some socially efficient optimum (ii) in pursuit of private payoffs framed as wins and losses." Every country wants to have safe and permanent access to energy and control over market prices for food. Analyzing conflict and peace using the Game Theory approach where two or more players try to maximize their utility could highlight the importance of the effect of the two commodities discussed above on peace and stability. The importance of the addressed topic derived from the fact of understanding political stability and its determinants in many countries. Without a stable state, a conflict could arise leading to tragic loss of life and physical destruction as well as economic damage. Here we are trying to investigate the relationship between stability and the two concepts of food and energy security.

Energy security is one of the rising subjects in modern economy as one of the grand challenges on a global level. All economic sectors rely on energy costs and availability. Renewable and alternative energy has been one of the active interesting fields of research during the last century due to many reasons, such as reducing dependency on oil, protecting economic growth, ensuring stability from price fluctuations and establishing sustainable energy plans. Ensuring continued and low tariff supply of energy and less environmental damage has led to the rising importance of the energy security concept.

The exponentially growing demand for energy in the last decades coupled with the concentration of oil in the world in just a few countries made the world more instable in terms of peace. MENA as one of the richest oil regions in the world is characterized by many conflicts and political instability. With the same growing demand for food over time as the world's population will reach almost nine billion in 2050 (FAO, 2009) the security concept is ever rising in importance as well. In the long run, additional factors came on top too like the demographic transition in the world financial instability and the rising concept of climate change. All this growing demand in terms of food and energy highlight the importance for every country to design their own policy or to regroup in specified organizations like OPEC.

A good strategic plan for energy security as well as food security should be based on a good price stabilizing system along with continued supply of both goods over time. This study implies the importance of the concept of ES and FS by identifying its effect on stability and 
peace. In the light of the above, the purpose of this work is to assess the linkages between food and energy security and political stability or peace within a country.

The motivation to address this topic came from the clear gap in the current literature of addressing the effect of the energy-food nexus on stability as well as from the will to contribute to the mechanism of understanding conflict management processes.

The following parts of this work will be organized as follows: the second section will look at the existing studies by analyzing both the theoretical and the empirical arms of the literature. A detailed definition and explanation of the three used concepts FS, ES and PS will also be presented in this part. For the third section we will present our research design which includes the formulation of a tested hypothesis, used methodology as well as data description. A detailed presentation of the new used indicator for stability which is the GPI index will also be provided in this part. In the last two sections of this study we will discuss the empirical results and conclude with recommendation and perspective. 


\section{2- Review of Literature}

\subsection{Review of theoretical literature}

\subsubsection{Energy Security}

Ever since the Industrial Revolution, energy has started to be a crucial factor in modern economy. Today the lack of access to energy is a major obstacle to the development of many countries. Energy related topics have become a strategic focus of state economic development policies. Many events also have shown the significant effect of energy related issues in the world. For example the embargo imposed by OPEC-States since the Israeli-Arab conflicts of the late 1960s resulted in a quadrupling of oil prices and through that plunged the world economy into recession between 1973 and 1975. This recession had serious consequences such as the gloom of the economy in the 1970s and inflation which lead to serious economic and social damage.

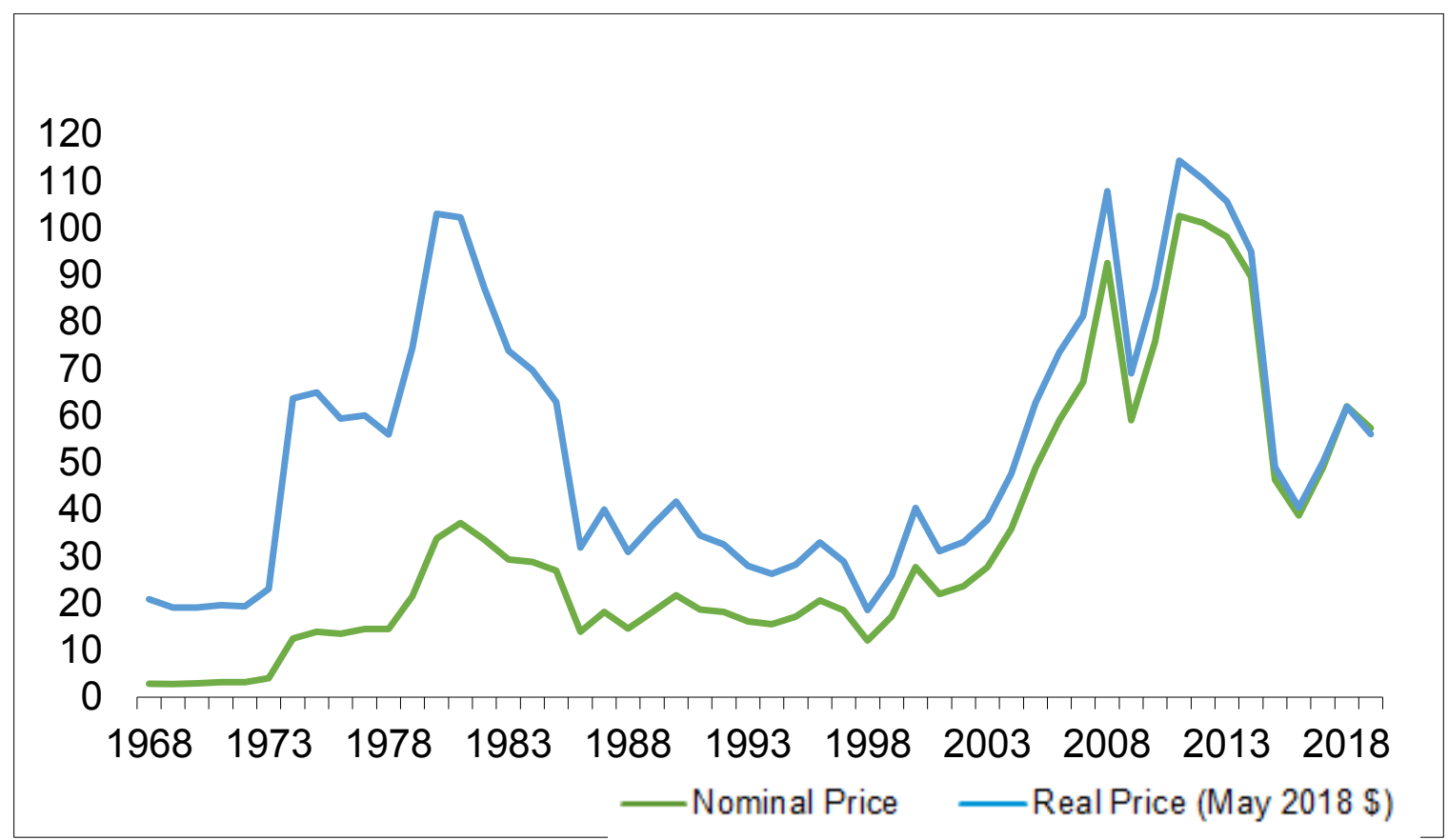

Source: EIA, 2018

Figure 1: Annual Imported Crude Oil Price 
Figures 1 illustrate annual oil prices from 1968 to 2018 (dollars per barrel). The first oil shock in 1973 was a consequence of the Arab-Israeli Yom Kippur War as presented the first pick in the graph. The second, in 1979, resulted from the Iranian crisis.

The disagreement between OPEC members resulted in a decrease in demand, the countershock of 1986 leading to the cancellation of the effects of the second shock. The Gulf War in 1990 caused a short time, less than a year shock, characterized by high prices. Finally, the upward trend of the 2000s accelerated the price per barrel from 53\$ in early 2007 to a high of $140 \$$ in July 2008. Again, a sharp drop brought the price down to $43 \$$ in early 2009 , before it quickly rose to more than 60 dollars a barrel. As shown in the graph, the oil price at the beginning of 1968 is multiplied by 5 in 1980. Between 1988 and 2003 prices were relatively low comparing to the previous period. What might be interesting in this figure is that oil prices are characterized by unexpected up and down movements. This price fluctuation affect the other economic sectors negatively. Some policies were adopted to hedge against this volatility such as compensation budgets. Still either a positive or negative oil shock in prices could harm all economic activity as well as food prices. All this has lead the world to look at the energy problem from another angle like energy source diversification.

Immediately after the oil crisis of the seventies, energy security concepts, specifically concerned with the availability and affordability of crude oil, have emerged in the area of global energy security and the macroeconomic stability program (Ilie, 2006). Initial efforts to strengthen energy security related to oil led to the creation of the International Energy Agency (IEA) in 1974, with the main objective of helping countries to coordinate collective responses to major disruptions to the supply of oil by the release of emergency oil stocks. The IEA has coordinated a series of measures on security, including the strategic management of reserves in Western countries to enable them to protect their economies from future oil problems (IEA Report, 2014). In recent years, with the cooperation of OPEC member countries on the stability of oil markets and the growing interest in maintaining a stable global macroeconomic state, the objectives of the IEA are oriented towards greater ideas such as energy security, economic development and environmental awareness.

The concept of energy security also concerns other limited energy resources such as coal and natural gas. The importance of oil in energy plans comparing to other energy sources come from its big share in energy consumption. Countries that have not taken part in the IEA framework have pursued their own energy security policies. 
For example, the successful diversification model developed in Brazil after the global oil shock highlighted traditional energy sources, particularly used in the transport sector, which have become very important in Brazilian society.

Energy security can be better understood if viewed within a wider context than the supply of oil, taking into account the production and distribution of electricity and the use of bioenergy sources, traditional and processed biomass. Biomass has a primarily local origin and is partly generated by biological processes in the context of long-term harvesting and environmental regeneration. The generation of electricity from clean energy sources such as hydroelectricity is governed by hydrological models linked to the risks inherent in climate change and drought. Dependence on imported energy sources entails serious risks since most of the factors that determine the supply of these sources and their prices are beyond the control of the importing States.

Scheepers et al., (2007) presented energy security as a risk of shortage in energy supply, which is either a relative risk (price changes) or a physical break in the supply of energy. This is why energy security is defined as the continuous supply of energy to consumers. Loschel et al., (2010) summarized energy security in many studies to build the physical availability of energy, energy prices and instability. By extending the sense of energy security to long-term concerns, Jansen and Seebregts, (2010) view energy security as an approximation of a certain level at which the population in a given region has unlimited access to fossil fuels and energy carriers based on fossils. The Clingendael International Energy Program (CIEP, 2004) still defines energy security as the physical and permanent availability of energy in sufficient quantities and at affordable prices, by differentiating themselves from a focus on the physical availability of energy for more cost-effective interpretations.

The European Commission (EC, 2001) targets long-term security by guaranteeing customers the physical and unlimited availability of energy products on the market at affordable prices for the well-being of citizens and the smooth running of the economy. In the same direction, the (IEA, 2007) presents energy security as physical availability of energy supply to meet demands at specified prices. This implies that energy insecurity stems from the physical disruption of supply and energy price surges. Other scholars like (Ang et al. 2015) in their review paper see energy security as a composite of seven dimensions that should be included to better define the concept. 
The dimensions are respectively: energy availability, infrastructure, energy prices, societal effects, environmental effects, governance and energy efficiency.

The key to ensuring a better energy security plan in an interconnected global economic system that is dependent on increasing energy consumption - and given the fact that international energy trade is expected to reach $142 \%$ in 2050 (Kruyt et al., 2009) - is diversification of energy sources, easy and safe access, inclusion of clean and renewable energy, better policy to hedge against price fluctuations as well as efficient and economic use of available resources.

Adding to the huge growing demand is the fact of unequal distribution of energy resources. So energy security is becoming a global concern. The impact of energy insecurity on economic systems is negative, but the extent to which regions and countries are willing to reduce these impacts differs considerably. The concentration of the supply of oil and gas resources in Middle-East and the volatile political environment in these countries aggravate the problem of energy insecurity. It is also clear that geopolitical phenomena's also determine the state of energy security in the world. The war in Iraq in 2003, the conflictual situation between Iran and the United States as well as the Arab spring are some recent geopolitical tensions that have had a direct impact on energy insecurity.

The strong relationship between energy and instability can be seen in many examples. Saritas and Burmaoglu, (2016) presented the huge increase in demand for energy over time in the military sector, arguing that during World War II the demand was going from 1 gal per solider per day up to 4 gal per solider per day in the desert storm operation in the 1990s. Another example for the importance of energy in warfare, the Pakistani-American oil crisis in 2011 that lead to the US providing a formal apology for the killed Pakistani soldiers after the Pakistani reaction of cutting oil supplies for US troops in Afghanistan back then. The Pakistani action cost the US around 700\$ million (World News Tomorrow, 2013).

On the other hand, improving energy security in a country could bring about some positive change including social and economic development, poverty reduction, private sector modernization and enhancing commercial balance. To test Energy security in our study we have used the variable of Energy imports provided in the WB data. We chose this variable as it expresses the desired effect to be tested and due to its availability in the time interval. 
Bert Kruyt et al., (2009) show in their review paper that there is no ideal indicator for energy security as each existing one has its own limitations. This variable will be presented in more detail in the coming parts of this study.

\subsubsection{Food Security}

Despite considerable efforts over decades, today more than 900 million people are experiencing food insecurity and daily hunger in this world. $75 \%$ of these poor people live in rural areas. While Asia has the highest number of hungry people in absolute terms, subSaharan Africa, with an average of $34 \%$, has the highest proportion of its population in food insecurity. In West Africa - one of the most affected regions - due to very large population growth and the degradation of natural resources as a production base, the number of people in food insecurity is likely to increase to between 100 million and 150 million in 2025, (FAO, 2015).

Global food security is a major issue for public policy, with the reduction of poverty and hunger being the first Millennium Development Goal (MDG). The state of natural resources, especially water, is increasingly becoming a limiting factor in meeting this challenge. Thus, the articulation between natural resources management and food security tends to take more and more space on the international political agenda. Given the fact that the world needs to produce more food with fewer resources while eliminating wasteful practices and policies is the harsh reality. Demographic changes, rising incomes, climate change, bad policies and inefficient institutions are leading to a shortage of natural resources. Rising energy prices have a negative impact on fuel and fertilizer costs for farmers, increase the demand for biofuel crops relative to food crops, and increase in the price of feedstock. Agriculture is already part of a context of land scarcity both in terms of quality and quantity: the best arable land in the world is already under cultivation and unsustainable agricultural practices have led to a significant deterioration of the soil. Applanaidu et al., (2014) used a VAR model in the case of Malaysia to show that food insecurity will also depend on population growth. In their result they have highlighted one of the intersections between food and energy security with their prediction of the negative impact of biodiesel production on FS objectives in the long run. The key factor of this interconnection is the land use. According to the authors the suggested solution in the case of Malaysia's overexploited land were agriculture investments offshores. 
The definition for FS by the Food and Agriculture Organization (FAO) holds that "food security, at the individual, household, regional, national, and global levels is achieved when all people, at all times, have physical and economic access to sufficient, safe and nutritious food to meet their dietary needs and food preferences for an active and healthy life" (FAO, 1996).

In fact, four components are identified: physical and the economic access, use (how the body optimizes different foods, hygiene), diversity of diet, distribution of food to and the stability of the three dimensions over time (FAO, 2008c). This widely accepted definition focuses on the following aspects of food security: Food Availability, Access to food, Use (which is use of food in an adequate diet) and Stability (which translates into permanent access to adequate food). To ensure this basic right, the concept of food security has been conceptualized by the FAO to eradicate hunger in the world. It refers to the four dimensions, however there still exists some ambiguity because it does not specify the origin of supplies, which may be local or international. This implies that each country must have a balance between national agriculture and the use of foreign trade according to its potential.

Today, armed conflict and malnutrition in the world are commonly seen attached to many regions leading to the destruction of more livelihoods, higher migration rates, and increasing poverty. Wilner Jeanty and Hitzhusen, (2006); showed the negative effect of conflict on food security in developing countries using the instrumental variable approach. Maystadt et al., (2014), also used a cross-sectional method on data from 1960 to 2010 to prove that with all the other drivers of conflict that came on line, food security is the key element of conflicts in the MENA region. They also concluded that more food security plans would secure the peaceful transition of the region.

Ensuring food security in the context of global change (climate, energy, population, etc.) is therefore probably the most important challenge to be met in the coming decades. This immense challenge will involve a combination of food security and water security considering their strong interrelations. Again the fight against food insecurity differs from the idea that the problem of hunger can be overcome simply by increasing agricultural production and by the need to fight poverty in general. Increasing agricultural production is important in itself, but it will not guarantee the well-being of the poor, who cannot afford to buy food, or small farmers who do not always have enough capital to buy means of production or lack adequate access to credit, water or a suitable infrastructure. 
Reducing poverty is, of course, a primary goal in itself, but it does not guarantee that those who are hungry benefit as much as other poor people, because hunger is not only a consequence but also a cause of poverty. A conception of trade liberalization based on the right to food by the reduction of barriers to trade might lead to an improvement of the situation in the countries suffering from famine or food insecurity.

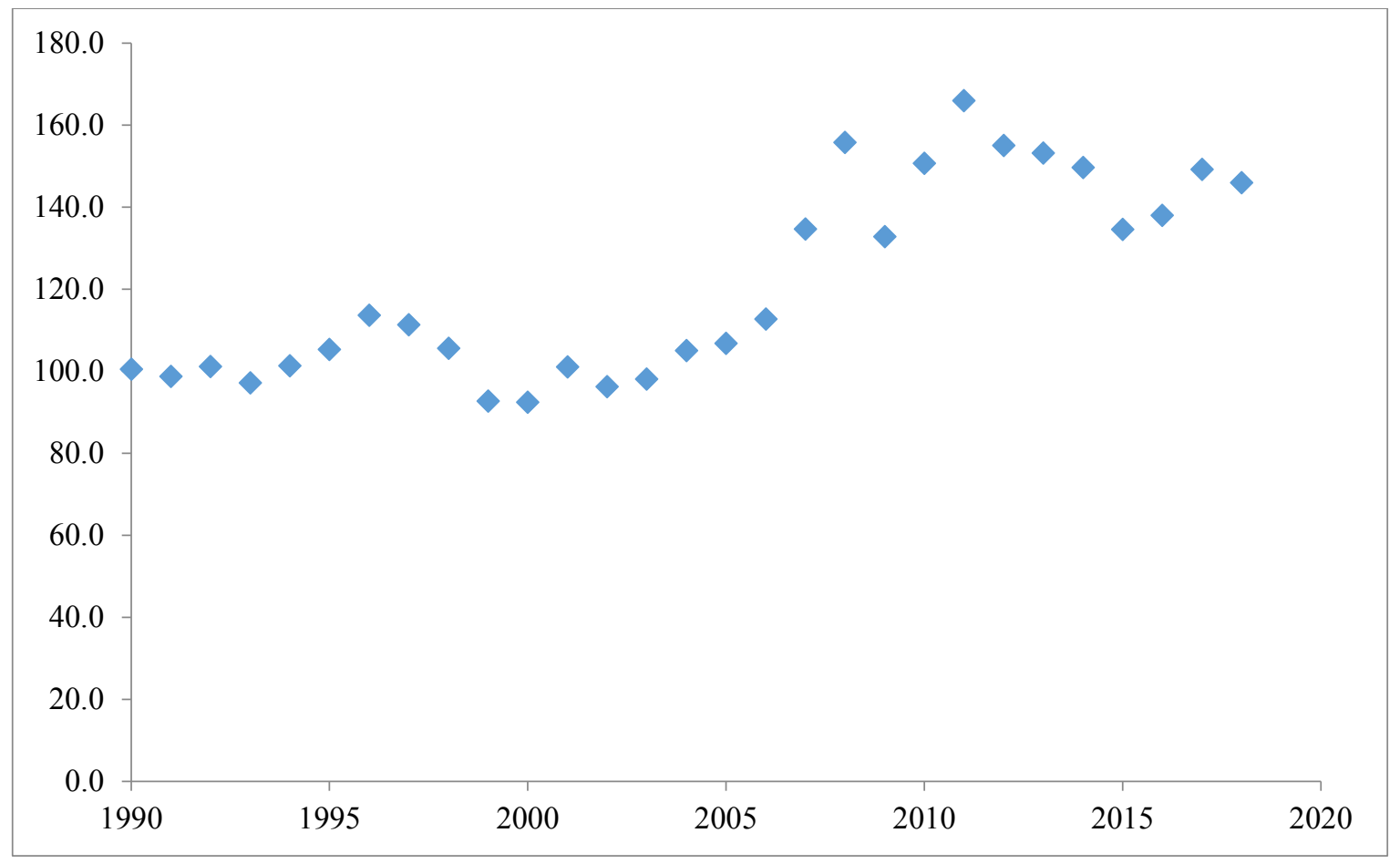

Source: FAO, 2018

Figure 2: Annual World Food Price Indices

Figure 2 illustrates world real food prices between 1990 until 2018. The FAO Food Price Index is a measure of the monthly change in international prices of a basket of food commodities. The weighted index reflects the prices of international markets of the five major groups of food products (meat, dairy, cereals, oils, sugar). The effect of the 2008 crisis can be seen clearly in this graph resulting in increased food prices. After reaching record levels in mid-2008, global food prices are generally on a downward trend, but many developing countries still face higher prices and much higher prices than in 2002 when they began to increase. Unstable or rising food prices have clearly increased the vulnerability of the urban and rural poor, whose purchasing power has been seriously eroded, resulting in both quantitative and qualitative deterioration of food prices. 
Rising food prices also have been attributed to a number of causes, including increased demand from the use of agricultural commodities for biofuel production and the economic development of densely populated developing countries such as China. Other indirect reasons are the rising of energy costs and prolonged drought in some of the major producing countries.

The same persistent problem of intermediary causing more speculation in international commodity markets is also an issue. Energy security plans need to take into consideration this food price volatility. The new trend of biofuel production seems to contribute in understanding the interrelation between food and energy. In the next paragraph we will provide a brief description of this interconnection.

The Food-Energy nexus has been discussed in many scientific work. The increase in oil demand combined with a decline in supply and stocks has led to a cyclical imbalance. Expansion of biofuels, rising oil prices, and increasingly pervasive speculation in agriculture are all triggers for a global food crisis. Biofuel as a new source of demand for agricultural products may represent an incentive for some developing countries to take advantage of agricultural growth to ensure rural development in general and reduce poverty initially. Biofuel-friendly policies were expected to contribute to energy security and mitigation of climate change through reducing greenhouse gas emissions while addressing the desire to support agriculture. But in the end it turned out to be one of the obstacles for food security in the long run due to its' competition in land use.

To test the effect of food security on stability we have used the variable of food deficit per person per day provided by the World Bank as a proxy variable. A further description of this variable will be presented in the next parts of this work.

\subsubsection{Political Stability}

Conflict and violence between groups of people or countries bring about a state of instability. Political stability with its broad definition includes the democratic level of country, absence of violence and how far people obey and respect the laws in the society. Ake, (1975) defines PS as follows: "Political stability is the regularity of the flow of political exchanges", meaning the need for regular exchange to avoid dictatorship. Stability does not mean an unchangeable and constant regime over time, but rather a stable state with no violence and conflict. 
Political stability has a major effect on a country's stability spanning from the economic to the social dimension. Bjorvatn et al., (2012) have found that political power balance could dampen the effect of oil resource curse and ensure economic growth within a country. Radu, (2015), has also concluded that political stability is a key factor for sustainable economic development. The effect of political stability and instability has been and still is one of the main topics in the literature.

Uddin et al., (2017) in their study, using the dynamic GMM and quantile regression methods on 122 countries have proven political stability to be one of the catalyzing factors for better economic performance and growth. Along with other factors (Al-Mulali and Ozturk, 2015) have also presented how political instability could increase environmental degradation using a sample of 14 MENA countries. Political stability could also reduce inflation and help stabilizing prices in a country. (Mazhar and Jafri, 2017) in their work about the determinants of inflations using data for 122 countries between 1999 and 2007 have found that political stability and inflation have a negative relationship.

Weak institutions due to corruption or political instability can hinder economic development. Absence of political stability could induce many risks for a country, despite the violence the other threats that a country could face is terrorism. Wu MengYun et al., (2017) have shown in their study that political instability favor terrorism attack to a country, which affect the financial sector and influence negatively investment as a major factor of economics growth. The study has been conducted for the case of Pakistan during the period from 2001 to 2014, considering the effect of the financial crisis of 2007/2008.

Another interesting study from the recent literature on political stability is by (Farzanegan and Witthuhn, 2017). In their paper the authors have shown how corruption coupled with a certain threshold of youth could help to increase political instability. Given the importance of political stability and peace keeping; (Bjorvatn and Farzanegan, 2015) showed how resource rent was used to keep stability in oil rich countries during the Arab spring movement.

Richard Jong-A-Pin, (2009), also investigated the different dimensions of political instability and its effects on the economic growth in a country using the dynamic panel system Generalized Method of Moments model (GMM) technique. His again analysis leads to the importance of stability as the instable state has a significant negative impact on growth. 
To measure political stability there are some indicators that could be used, like the International Country Risk Guide published by the Political Risk Services (PRS) group or one of the World Governance Indicators (WGI), which is Political Stability and Absence of Violence (see, for example; Bjorvatn and Farzanegan, 2013, Witthuhn and Farzanegan,2014). To reflect political stability in our study we used a new variable compared to the one used in previous studies. The proxy variable used is the Global Peace Index from the IEP institute. A further description will be provided in the following parts of the thesis.

Table 1: Worst countries in GPI ranking

\begin{tabular}{|c|c|c|}
\hline Country & Aggregate Score & Ranking \\
\hline DPR Korea & 2.849 & 150 \\
\hline Russia & 2.967 & 151 \\
\hline Pakistan & 3.047 & 152 \\
\hline Democratic Republic of the Congo & 3.058 & 153 \\
\hline Ukraine & 3.061 & 154 \\
\hline Central African Republic & 3.213 & 155 \\
\hline Sudan & 3.213 & 155 \\
\hline Libya & 3.328 & 157 \\
\hline Somalia & 3.387 & 158 \\
\hline Yemen & 3.412 & 159 \\
\hline South Sudan & 3.524 & 160 \\
\hline Iraq & 3.556 & 161 \\
\hline Afghanistan & 3.567 & 162 \\
\hline Syria & 3.814 & 163 \\
\hline
\end{tabular}

Source: IEP, 2017

Table 1 above presents the last countries in the ranking list of 2017 according to their GPI index. We see clearly that Syria is on the bottom of the list. Syria in terms of stability is considered to be the worst as the conflict has started during the Arab spring movement and persists until today. We can see that most of the listed countries are from the MENA region. One of the main characteristic of this region in the world is that it's scarcity in terms of water and its richness on oil. Oil and stability have been investigated in the literature as well. Usually the stability and resource relationship has taken the form of both side in the literature. 
The question of resource or specifically oil has been investigated as of blessing or curse. Resource curse has been identified by many scientist; see for example (Mehlum et al., 2006; Papyrakis and Gerlagh, 2004; Mobarak and Karshenasan, 2012) as their main arguments and analysis were based on the economic impact of the resource wealth within a country. Resource rich countries have been identified to have slow economic growth. Results show that there exist a negative relationship between growth and natural resource abundance. This result was explained in reality through transmission channels. Some of the discussed channels were investment and corruption as the negative resource effect in a country will decrease entrepreneurship and might increase corruption. This negative effects on growth and investment are indirectly related to stability.

A stable country seems to have a better economic situation according to the literature. Some other scholars proved the blessing hypothesis of natural resource (for example Alexeev and Conrad, 2011; Brunnschweiler, 2008; Brunnschweiler and Bulte, 2008; Pendergast et al., 2008). They argued that resource rent in a country could help boosting economic growth. The surplus generated by this resource could be used in different economic sectors to allow for more technological progress. Resource rent's positive impact on economic development in a country might influence stability positively. For example Australia and Norway have been ranked 12 and 14 respectively in terms of the GPI index in 2017. These two resource rich countries succeeded to reach higher stability and economic growth comparing to the ones listed in Table 1. Stability is a result of existing conditions in a country. Reaching stability level should be the objective of every government and political system. To attend this objective a deep analysis on understanding the mechanism and transmission channel is needed. In the next part we will go through the literature to identify the factors that affect stability according to existing previous work.

\subsection{Review of empirical literature}

In this part we will go through the related Empirical studies in the literature. Many determinants of stability have been identified. Land is one of the important factors that influence the stability in a country and on the international level as well. Boone, (2017) in her paper about soil conflicts in African countries showed that the quality of a state's institutions matters in solving conflicts over land. 
Land scarcity is one determinant in conflict between land owners and immigrants. For this reason we are going to consider percentages of arable land per country over the selected time interval as control variables in our analysis.

High fertility rate and rapid demographic growth might affect both the economic development and the PS in a country. Assaad and Roudi-Fahimi, (2007) also proved the negative effect of a high fertility rate on the MENA region. On the other hand some scholars like (Bloom \& Williamson, 1998) and (Bloom et al., 2000) have shown that the demographic transition could be the reason of economic growth and therefore more stability, given the example of Asian countries. But what still remains persistent is that an increase in the working age population with poor economic conditions leads to more unemployment. According to (Fearon and Laitin's, 2011) internal conflict could be fueled by internal changes like high unemployment and migration that occur over time within a country.

The rise of population density caused by high fertility rates and immigration waves could increase ethnic heterogeneity and competition between groups. The theory of high fertility resulting in a rapid increase in population density and high demand for goods and jobs will also be tested in our work as one of the determinants for stability across time and countries. The unemployment factor will also be included in our study. Qiong and Junhua, (2015), investigated the relation between military and non-military expenditure in regard to unemployment rates in China using the Autoregressive Distributed Lag (ARDL) model approach for data, covering the period from 1991 to 2013. Their main finding was that defense spending increases unemployment rates where non-military spending decreases the rates allowing for more work opportunities. As military spending as a share of GDP we could see that stability promoting less defense spending could lead to low unemployment leading to more spending in the other economic sectors, like agriculture and industry.

Openness and globalization have also been tested as a main variable in their relation to stability. Amavilah et al., (2017) conclude in their paper, about the effect of globalization on peace and stability in 53 African countries from 1996 to 2010, using three stage regression techniques that a positive and significant effect of trade on peace and stability exists. More trade, more cooperation and less conflict. Also (Goklany, 2002) see that globalization reduces hunger. Globalization expressed by trade or FDI will reduce barriers, resulting in a more liberated market, which will help achieving the food security goal. 
Another strand of literature, like (Rodrik, 1997), presented a negative relationship between foreign direct investment and stability that might transmit an external shock to the host countries, which influence peace and stability. This result was explained due to the poor quality of institutions. Messer and Cohen, (2006). Also explained in their work how openness could influence market prices and increases volatility which threaten the food security objective.

Corruption, inequality and dictatorship are all factors that might influence stability as well and like so stimulate conflict in a country. David and Bar-Tal, (2009), argued that economic inequality and injustice mobilize conflict and reduce peace. Also (Haass and Ottmann, 2017), investigate in their study that power sharing, foreign aid and natural resources in post conflict countries could increase corruption, using time series and a cross-sectional analysis of postconflict situations during 1996-2010. These results is that the high corruption level could affect the long term economic and institutional quality of a country. Another study on the effect of corruption on stability is by (Fjelde, 2009).

It has shown that people in power in a corrupt government could use natural resource rent in their favor in order to keep or "buy stability". For example resources like oil rent have also been used by governments of oil rich states to buy peace and to stay in power. For example the government in Kuwait has distributed money, almost about a 1,000 Kuwaiti dinars to all the citizens with free food staples for 13 months (Calderwood, 2011).

Aguirre, (2016), also utilize an empirical approach using a theoretical institutional technique to prove that a higher risk of future conflict is related to lower constraints imposed on the executive or the elite. More constraints and pressure on the elite will lead to more redistribution as the main goal is the reduction of revolutionary impulse which might threaten their present status. This was seen obviously after the Tunisian revolution in 2011 that catalyzed the start of a series of events and resulted in changing the geopolitical situation of the MENA region. Ethnicity and cultural dimension could have a certain effect on political stability as well. Corvalan and Vargas, (2015) have used a world sample of countries from 1960 until 2000 to investigate the relationship between segregations and conflict by estimating a cross sectional model. The main result of the empirical analysis was a robust correlation between both language and ethnic segregation and conflict; and especially no evidence of the effect of religious segregation on conflict. 
As ethnicity and language and many other time invariant factors could influence our result we will use the fixed effect method as suggested by the statistical approach of the HausmanTest in order to cross out any sort of result bias. A further explanation of the method will be provided in the methodological part.

Several scholars also wrote about tourism as a peace maker and how it helps people from different nations and cultures to communicate and interact in a good way. Reducing the psychological and social gap between people in the world and bring them together away from media and negative political effects will lead to more peace (Askjellerud S., 2003; Nyaupane et al., 2008; Causevic, 2010; Sarkar and George, 2010). A new study conducted by (Farmaki, 2017), highlighted the effect of tourism in peace building and how it serves as a steppingstone for ending violence. The mediator effect of tourism could be explained through some respective channels and interaction, like education (Collier and Hoeffler, 1998; Collier and Hoeffler, 2004). Resource rent has also been identified to be one of the factors that might affect stability. Oil rent and its negative effect on economic growth which indirectly also affects stability within a country was investigated by (Issifou, 2016).

In his analysis about migration and conflict he proved the negative relationship between natural resources and conflict. His main finding was that interaction between migration and natural resources can dampens the natural resource curse on economic growth. Siddiqi, (2013), in his article Pakistan, India, China, and the United States: Energy, Climate Change, and National Security highlighted the relationship between energy and national security being paradox in terms of conflict. The project of a Natural Gas Pipeline to import gas to Pakistan and India from Iran has been stopped by the US to date due to sanctions imposed on Iran back then. This could explain how conflict can block energy security objectives in some countries. The American-Iranian conflict stemmed from Iranian Nuclear activities when this country started to execute a national energy security plan. The question that could arise is whether nuclear energy used in terms of alternative energy plans could or could not lead to more conflict in the long run. Nuclear Energy use could result in reducing peace in the world as this technology has effects on two sides depending on the objective of use: either energy production of destructive weapons. 
To summarize the main factors mentioned in the literature Figure 3 below illustrates the factors that affect stability within a country. The upper part presents the factors that are defined in previous studies. For example growth, tourism and globalization translated into trade or FDI are the factors that positively affect stability. Other destabilizing factors found by previous studies are corruption, unemployment, high fertility rate and land scarcity. Some of these variables are determined to have a negative relationship with stability due to their indirect effect. For example corruption and high fertility rate are known as elements that are correlated negatively with economic growth. The unemployment factor might have both negative and positive effects on growth. Some studies have shown that high rates will lead to more unemployment which will affect economic growth and stability within a country (Assaad and Roudi-Fahimi, 2007, Fearon and Laitin's, 2011).

Other scholars went to the other side of the theory around high fertility rates arguing that a high rate and population growth has played a major catalyzing factor in the rapid economic development of some Asian countries. For example China has used the growing available labor force in the country to boost the economic development. Having vast labor resources in the country is factor to start producing at low prices and improve competiveness in an international market.

For example (Bloom and Williamson, 1998) and (Bloom et al., 2000) showed that high fertility with population growth catalyzes the economic development in a country, which will positively affect stability. Given these mentioned variables that have been investigated by the literature, this study will go for further investigation concerning the determinant of stability. 


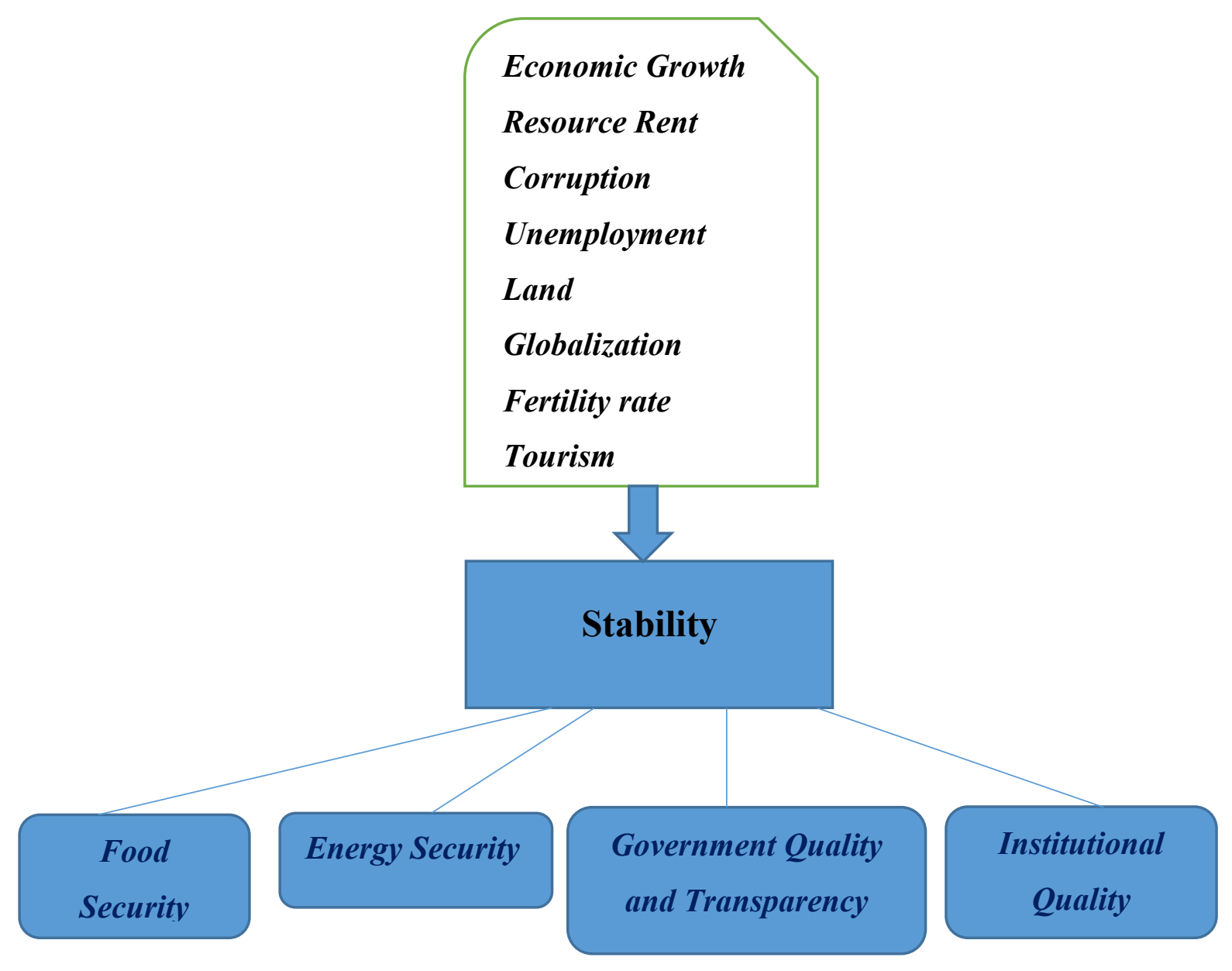

Figure 3: The new tested variables

As shown in Figure 3 above we will try to test the relationship between stability and energy security. As ES is a rising topic currently, the need to understand what kind of relation exists between energy and stability is crucial. The idea of testing this assumption comes from the rising conflict over energy sources all around the world; and to answer one of the most important question's does reaching the energy security goal in a country help to have a stable political system. The tested rectangle of energy as presented in the figure in this interrelated subject is somehow also related to economic growth. Establishing a successful energy strategy in a country will give a window of economic stability and also has its indirect effect on political stability.

The second element to be tested in this work is the food security as shown in Figure 3. Food security has the same weight of importance as energy security in a country. Improving a food situation will help reducing poverty. Ensuring a continued supply of food over time with stable prices will also improve economic growth and stability within a country. 
To reduce dependency some countries need to start working on their food security plan which will promote stability as well. The third new tested element is the institutional quality. Law and institution are primordial in ensuring stability within a state. Enforcement of law with high institutional quality will reduce inequality and promote justice. In a country the economic dimension is as important as the social one. Equality and justice between citizens will reduce the probability of conflict and instability. As well as a good government quality and transparency. This fourth factor is assumed to affect stability in an indirect way. A transparent system within a country will decrease corruption which will help economic growth and therefore promote stability. A further explanation of the methodology and the tested hypothesis of this work will be presented in detail in the coming parts. 


\section{3- Research Design}

\subsection{Hypothesis}

As explained in the previous parts of this study, political stability plays a major role in country development. Stability as a context might include the holistic concept of Peace, as well as absence of violence, conflict and terrorism. It also spans to the regime type that is adopted by a country and its degree of democracy. Many scholars investigated the effect of stability on growth. Moshi and Mwakatumbula, (2017) showed the positive effect of political stability on Investment in Africa. Stability has also been proven to be a main determinant of economic growth (see for example Uddin et al., 2017; Tabassam et al., 2016; Radu, 2015). On the other hand the instable state could bring harm to the different economic sectors of a country as well as the social dimension. Elbahnasawy et al., (2016) argue that instability will help the expansion of the informal economy within a country as people will scape meeting standard production rules. A further investigation by (Mazhar \& Jafri, 2017) shows that instability will cause an increase of the inflation rate through the extension of shadow economy within a country. The idea to look at the different factors that might influence stability came from the importance of this condition in a state to ensure economic and social development. Many analyses in the literature find positive and negative correlations among determinants of peace and stability.

Food is essential for the human body to stay healthy and productive as well as energy is important for an economy to maintain growth and productivity. Food and energy are the primordial elements for humans to survive not only from a vital dimension but also through influencing conflict and peace. This could also be realized through institutional management channels as the Arab spring movement has shown in some oil rich countries. The need for examining more factors that can affect stability and following the work of (Farzanegan \& Witthuhn, 2017) who demonstrated the negative effect of corruption on political stability, our study will try to examine the effect of FS and ES. In the light of the above, the purpose of this study is to assess the linkages among food, and energy security and stability controlling for other determinant and variables. 
Thus, the Hypothesis of this work is: Food and energy security are positively affecting political stability. The general model to test the validity of this hypothesis is derived from political stability and its determinants from the literature (see for example Bjorvatn and Farzanegan, 2013; Witthuhn and Farzanegan, 2014, Bezemer and Jong-A-Pin, 2013, Bjorvatn et al., 2012).

Model (1) below shows our first conceptual relation which includes a response variable reflecting stability and set of explanatory variables as well as a set of control variables. The model has the form as presented here:

$$
R_{i t}=\alpha+\beta_{1 * \mathrm{E}_{i t}} \beta_{2 *} \mathrm{Z}_{i t}+\mathrm{e}_{i t}
$$

Where $\mathrm{i}=1, \ldots, \mathrm{N}$ ( $\mathrm{N}$ denotes the total number of countries); $\mathrm{t}=1, \ldots, \mathrm{T}$ ( $\mathrm{T}$ denotes the total number of years); $R_{i t}$ denotes Stability in country $i$ in year $t ; Z_{i, t}$ is a vector of endogenous explanatory control variables that has been identified from previous studies and scientific publishing for country i in year t. These variables include for example GDPpc Openness, Fertility rate, Tourism, etc. They are included to reduce the omitted variable bias in the model and test for the validity of the tested variables after controlling for other factors. The parameter $\mathrm{E}_{\mathrm{it}}$ is a vector of endogenous explanatory variables of interest (e.g. FS, ES, Institutional quality) for country $\mathrm{i}$ in year t. Finally, the error term $\mathrm{e}_{\mathrm{it}}$ is assumed to be independent and identically distributed. In this model, the response variable $(\mathrm{R})$ describes stability. In general this dependent variable is measured either through the International Country Risk Index or one of the World Governance Indicators (WGI), which are Political Stability and Absence of Violence. But in this study we will use a new indicator, which is the $G P I$ index from the IEP institute.

The corresponding research questions for this work are: What is the relationship between FS, ES and stability, and how does such a relationship affect political change in a country? Could improving food security reduce the conflict and call for more peace and stability? And how far could good governance and institutional quality secure peace and stability. The rationale and motivation for asking and pursuing these research questions are that there is a clear gap in the current literature on the effect of food and energy on stability within a country. In this work we also will contribute to the literature by using a new stability indicator, being the GPI Index from the IEP Institute. 
Table 2 below shows the list of the explanatory variables and their expected signs. The variables are to be tested in order to investigate the validity of our Hypothesis. The variables GDPpc, TNR, Unem, Tourism, AR_Land, CC and FDI serve as control variables whereas FD, EI; R_Law and V_Acc are our main variables of interest. As mentioned in the Table we expect to have a negative impact of food and energy insecurity on stability. Stability is presented in this work by the Global Peace Index from the Institute of Economic and Peace. The mentioned World Governance Indicators are used to test the impact of the quality of government and institution on stability. We assume that there exist some moderating channels in the relationship between stability and other factors.

Table 2: Explanatory Variables and Their Expected Signs

\begin{tabular}{|c|c|c|c|}
\hline $\begin{array}{c}\text { The symbols of } \\
\text { Explanatory Variables }\end{array}$ & Explanatory Variables & $\begin{array}{c}\text { The sources of } \\
\text { Explanatory Variables }\end{array}$ & Expected Signs \\
\hline GPI & Global Peace Index & $I E P$ & \\
\hline GDPpc & $\begin{array}{c}\text { Gross Domestic Product per } \\
\text { capita }\end{array}$ & $W D I$ & - \\
\hline TNR & $\begin{array}{l}\text { Total Natural Ressource as share } \\
\text { of GDP }\end{array}$ & $W D I$ &,+- \\
\hline Unem & Unemployment Rate & $W D I$ & - \\
\hline Tourism & Number of Tourist & $W D I$ & - \\
\hline AR_land & Aable land & $W D I$ &,+- \\
\hline $\mathrm{CC}$ & Control of Coprruption & $W G I$ & - \\
\hline FDI & Foreign Direct Investment & $W G I$ & - \\
\hline EI & Energy Imports & $W D I$ & + \\
\hline FD & Food Deficit & $W D I$ & + \\
\hline V_Acc & Voice and Accountability & $W G I$ &,+- \\
\hline R_Law & Rule of Law & $W G I$ & - \\
\hline
\end{tabular}

Source: author's illustration 


\subsection{Panel methods}

In this part we will present the type of Data to be used, its characteristics and the different commonly used approaches on this data. Panel data or longitudinal data refers to a data set containing observations on multiple phenomena over multiple time periods. Thus, it has two dimensions: spatial (cross-sectional) and temporal (time series). Panel data are characterized by the presence of two dimensions across countries and across time. The reasons behind using these types of models is that this data allows to control for unobservable factors like culture, geographical specification or variables that change over time but not across countries (Vijayamohanan, 2016).

It also brings a more accurate result where the economic models are closer to reality in terms of analyzing effects on or relationships between variables. Dealing with this kind of data the most commonly used methods are the fixed and random effect models. A standard assumption in these panel models is that the error terms are independent across entities. These two models allow for heterogeneity across panel units. The fixed effect model is used because of its advantage concerning the data heterogeneity problem. Independent of how large the regressor list is there should exist unobserved factors that are not generally detected by normal OLS regression, which causes inconsistent and biased OLS estimators. One advantage of the fixed effect method is that a fixed effect estimator does not require a balanced panel. Besides, the fixed effect model treats the error term as a random variable under the assumption that there might be a correlation between the error and some parameters. This assumption is based on the presence of a time varying component which is cancelled out by taking the difference of the average on time. This modification is called (within transformation) and presented respectively in model (2) and (3) below.

$$
\begin{aligned}
& y_{i t}=X_{i t} \beta+\alpha_{i}+u_{i t} \text { for } t=1, \ldots, T \text { and } \mathrm{i}=1, \ldots, \mathrm{N} \\
& y_{i t}-\bar{y}_{l}=\left(X_{i t}-\bar{X}_{l}\right) \beta+\left(\alpha_{i}-\overline{\alpha_{l}}\right)+\left(u_{i t}-\bar{u}_{l}\right) \Rightarrow \quad \ddot{y}_{l t}=\ddot{X}_{l t} \beta+\ddot{u_{l t}}
\end{aligned}
$$

Contradictory to the fixed effect the random effect model works under the assumption that there is no correlation between the error terms and the regressors. Therefore the time invariant variables are included and estimated as one of the independent variables. 
This model (4) presented below counts for heterogeneity and difference between entities as they might have an effect on the tested relationship.

$$
y_{i t}=\beta_{0}+\beta_{1} x_{i t 1}+\cdots+\beta_{k} x_{i t k}+\underbrace{a_{i}+u_{i t}}_{\begin{array}{c}
e_{i, t}=a_{i}+u_{i, t} \\
\text { composite error }
\end{array}} \text { for } t=1, \ldots, T \text { and } \mathrm{i}=1, \ldots, \mathrm{N}
$$

Choosing one of the two models is generally based on the data and the goal to be achieved. If the objective is to investigate the effect within entities and we believe that there are common factors between some entities in the data that could influence the result, the fixed effect model will be the appropriate approach (Borenstein et al., 2010). On the opposite side if our goal is to take the time invariant effect into consideration. As part of the explanatory variables the random effect will do the job as this component is not cancelled out like in the fixed effect approach. Some mistakes to be avoided during the selection process of the model as described in the paper of (Borenstein et al., 2010) are that it would be impeditive to start using the fixed effect model in the regression process and then switch to the random effect one. One reason for that is that the fixed effect estimator's weights are based on within-entities variance whereas the random effect weights are based on within and between-entities variance. It might look like the fixed effect model is just a special case of the random effect model but still both models are based on different assumptions for e.g. The error term, data scattering and the effect to count for.

\subsection{Methodology}

For our work we followed the methodology as explained in this part. We modeled the link between political stability, food and energy security as a five-stage process. We put forward one hypothesis, and applied a fixed effect regression technique which we focused on within country variation (see Bezemer and Jong-A-Pin, 2013 for a similar approach) to estimate and test this hypothesis. In the first stage we associated peace and stability with energy import as a proxy for energy insecurity along with corruption, and foreign direct investment (FDI) as measures of openness and further other control variables as listed in Table (5a) in the next section4. 
In the second stage, we added the variable of food deficit as an indicator for food insecurity. In the three remaining stages we included a more intense food insecurity state (squared term of food deficit) as well as institutional and governmental quality indicators respectively. Fixed effect regression was used for three main reasons. First, because we assumed that some effects within countries that are unique to certain entities or groups should not be correlated with the dependent variable. These specific time invariant factors might bias the outcome variable like culture and norms, etc. Secondly, our variables are varying over time, which is one condition to use this kind of approach. Finally the FE method removes the effect of those time-invariant characteristics by the within transformation technique so we can easily assess the net effect of the predictors on the outcome variable. To ensure that our assumption is in line with data distribution we have used the so-called Hausman Test from Stata Software. The HT basically tests the error term in both models, RE and FE. The null hypothesis in this discussed test is that the preferred model is random effects instead of the alternative fixed effects (Green, 2008). The five regressions have shown a significant result for the HT test, which allows us to reject the null hypothesis and therefore the FE is the appropriate approach.

A series of other tests was also performed to test the statistical validity of our model. First we operated a test using Stata software to see if time fixed effect is needed with the FE model or not, which is a joint test to examine if the dummy for all years is equal to zero or not. The result of this test showed that no time fixed effect is required for all specifications. The second step was to test for cross sectional dependence using the Breusch-Pagan LM test of independence. But following (Baltagi et al., 2012) that this problem does not occur in sample of panel data with few years $(\mathrm{T})$ and large number of countries $(\mathrm{N})$, and given the fact that our data time range spans from 2008 until 2016 with a nine years interval (small T) we have excluded this test from our modeling process.

The last test in our used methodology process was the test for heteroscedasticity. To avoid any problem about the constant assumption of the variance we have used the robust option in our modelling demarche in all regressions. Testing for serial correlation was also eliminated due to its necessity only in the case of panels with long time series (over 20-30years), which is not a problem in micro panels like ours (9 years). As set the next part in this study will present the data set in details. All explanatory variables in the five regression stages are lagged one year to reduce possible endogeneity problems (see Bjorvatn, Farzanegan and Schneider, 2012; Bjorvatn and Farzanegan, 2013 for a similar approach). 


\subsection{Data}

\subsubsection{Independent variables}

\subsubsection{Variables of interest}

Our variables of interest are proxy variables collected from the World Bank database. These variables reflect the situation of energy and food insecurity in countries. We will go through a detailed description of these data in this part.

\section{Food Security}

FS is expressed by the depth of the food deficit. FS indicates how many calories would be needed to lift the undernourished from their status. It is measured by kilocalories per person per day. It presents an estimation of the total food deficit in the country, normalized by the total population. According to the collected data the values span from 1, which shows a relatively good FS in a country to more than 500, which shows the opposite, a bad food security situation. Data is collected from WB Database covering 152 countries over a period of nine years (2008-2016). This variable was available for the selected time period and all countries and has been chosen as an independent variable. It is presented in the models and the database as (FD).

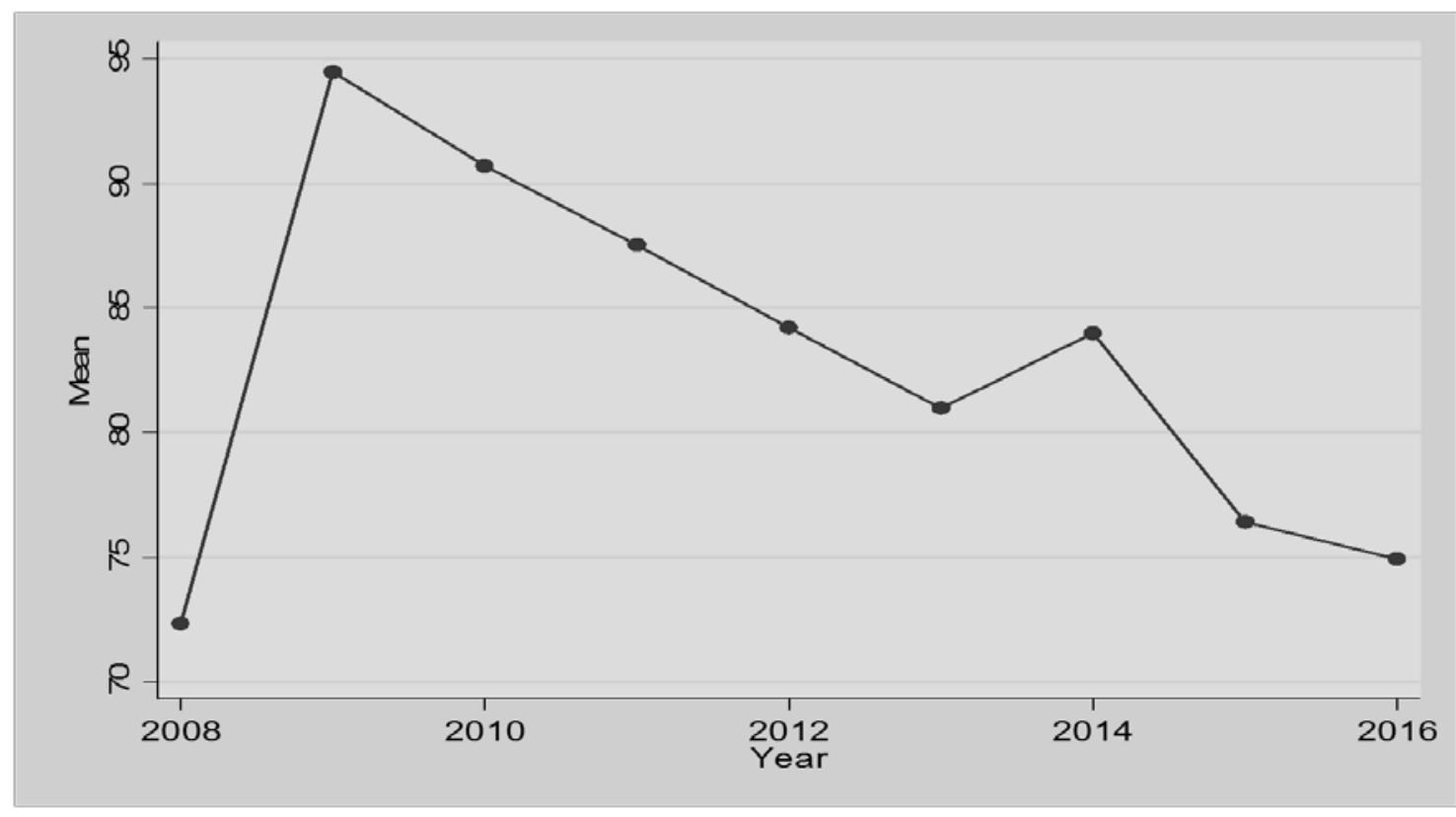

Source: author's illustration

Figure 4: Average Food Deficit worldwide sample 
Figure 4 illustrates the evolution of the food deficit (Kcal), in the world from 2008 until 2016. There is a clear decreasing trend over time, which shows an improvement of the food situation in the world. Another remarkable change is seen in the year of 2008 where we see an increase in food deficit in our world sample. This could be explained by the finical crisis of 2008 which has influenced food prices and availability. According to the tested hypothesis in this study food insecurity will lead to instability. Another used variable in this work is the squared term of food deficit which reflects a more intense situation for the food insecurity in a country. The variable is described below.

\section{Food Security squared}

This variable is again the depth of food deficit but this time in squared term. It is unserved by the deficit of kilocalories per person per day in a country and it is presented in the models and database as (FD_sq). The variable counts for a more intense state of food insecurity within a country.

\section{Energy Security}

ES is reflected by the net energy imports in country. Values are estimated as energy use minus production. Both are measured in oil equivalents. A negative value indicates that the country is a net exporter and a positive one indicates that it is net importer. Data was collected from World Bank Database covering 152 countries over a period of nine years (2008-2016). This variable was not available for the whole selected time period and all countries, and therefore has caused a reduction of our sample size. It has been chosen as an independent variable. It is represented in the models and the database as (EI). 


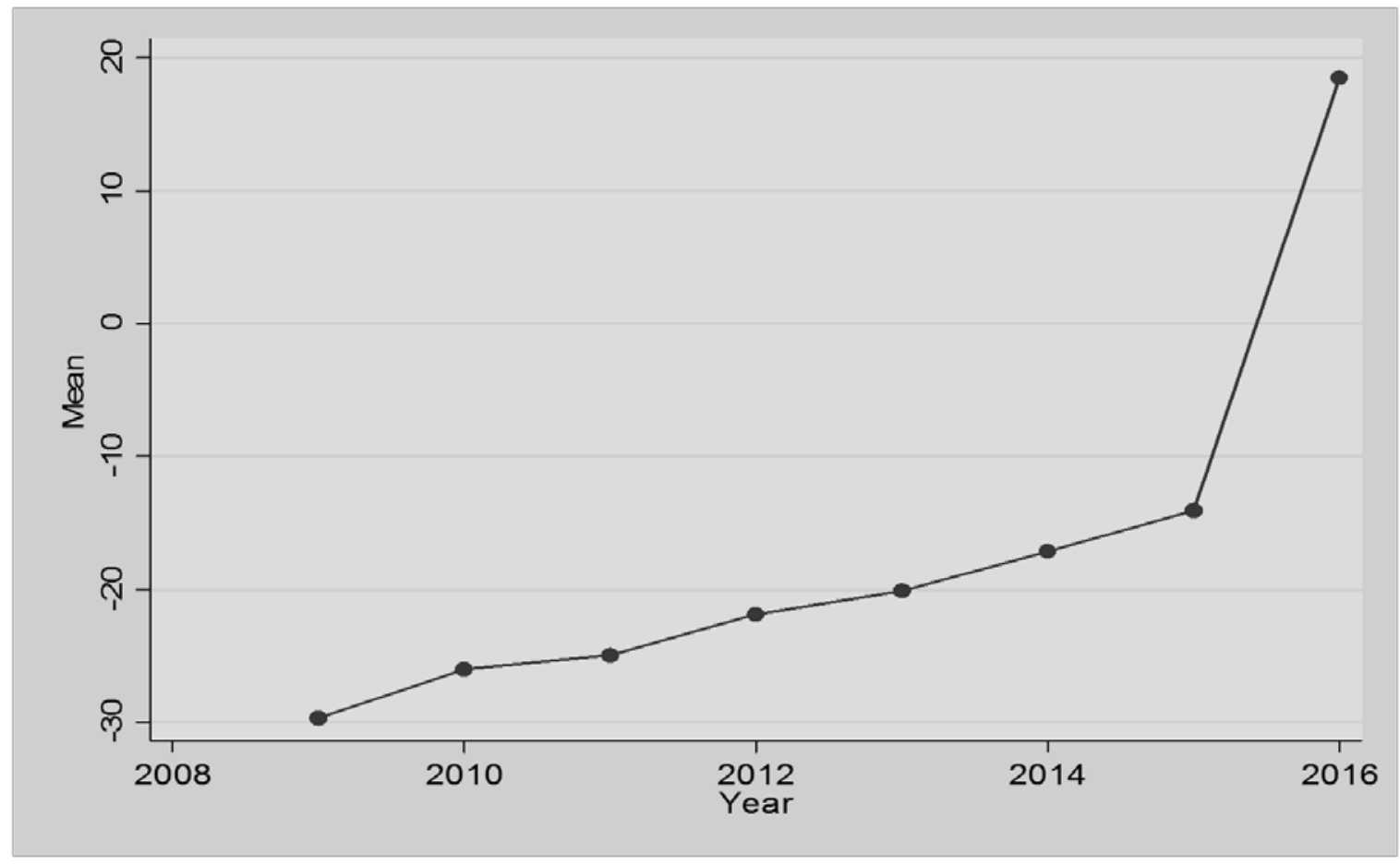

Source: author's illustration

Figure 5: Average Energy imports worldwide sample

Figure 5 illustrates the change of energy imports in the world over the chosen time period from 2008-2016. An increase in energy imports could be assigned to the vastly increasing demand for energy over time. The world is consuming and importing more and more energy. An instable energy security state within a country to hedge against this change in energy prices and availability will lead to more instability as expressed in our hypothesis.

\section{Government Quality and Transparency}

Government quality and transparency is expressed through the Voice and Accountability Index. It captures perceptions of the extent to which a country's citizens are able to participate in selecting their government, as well as freedom of expression, freedom of association, and free media. Values in units of a standard normal distribution are ranging from -2.5 to 2.5. Data was collected from WGI of the World Bank covering 152 countries over a period of nine years (2008-2016). This variable was available for the whole selected time period and all countries and has been chosen as an independent variable. It is presented in the models and the database as (V_Acc). 


\section{Institutional Quality}

This variable is expressed by the Rule of Law Index. It captures perceptions of the extent to which agents have confidence in the rules of society, the quality of contract enforcement in particular, property rights, the police, and courts. This index has values going from -2.5 to 2.5 . Data was collected again from the World Governance Indicators of the WB covering 152 countries over a period of nine years (2008-2016). This variable was available for the whole selected time period and all countries and has been chosen as an independent variable. It is presented in the models and the database as (R_Law).

\subsubsection{Control variables}

In this part we will give a detailed presentation of the used control variables. These variables were selected based on the literature discussed previously.

\section{Economic Growth}

Economic growth is expressed by the annual percentage growth rate of GDP per capita based on constant local currency. Data is collected from World Bank National Accounts data, and OECD National Accounts data files. Data is covering 152 countries over a period of nine years (2008-2016). This variable was available for the whole selected time period and all countries and has been chosen as a control variable. It is presented in the models and the database as (GDPpc).

\section{Resource Rent}

Resource rent is expressed by the share of total natural resources rents (sum of oil, natural gas, coal, minerals, and forest) in the GDP as percentage. Data was collected from the World Bank Database covering 152 countries over a period of nine years (2008-2016). This variable was available for almost the whole selected time period and almost all countries and has been chosen as an independent variable. It is presented in the models and the database as (TNR). 


\section{Corruption}

Corruption is expressed by the Control of Corruption Index. It captures perceptions of the extent to which public power is exercised for private gain. Values are ranging from -2.5 with more corruption to 2.5 with less corruption. Data was collected from the World Governance Indicators (WGI) of the World Bank covering 152 countries over a period of nine years (2008-2016). This variable was available for the whole selected time period and all countries and has been chosen as a control variable. It is presented in the models and the database as (CC).

\section{Unemployment}

Unemployment is expressed by the unemployment rate. It refers to the share of the labor force that is without work but available for and seeking employment. Data was collected from the World Bank Database (International Labor Organization, ILOSTAT database) covering 152 countries over a period of nine years (2008-2016). This variable was available for the whole selected time period and all countries and has been chosen as a control variable. It is presented in the models and the database as (Unem).

\section{Land}

This variable is expressed by arable land measured by hectares per person and includes fertile land defined by the FAO. Data was collected from WB Database covering 152 countries over a period of nine years (2008-2016). This variable was not available for the whole selected time period and all countries and has been chosen as an independent variable. It is presented in the models and the database as (AR_land).

\section{Openness or globalization}

Openness or globalization is expressed by the foreign direct investment net inflows (current US dollar \$) and refers to direct investment equity flows in the reporting economy. Data was collected from WB Database covering 152 countries over a period of nine years (2008-2016). This variable was available for the whole selected time period and all countries and has been chosen as an independent variable. It is presented in the models and the database as (FDI). 


\section{Fertility rate}

Fertility rate is expressed by the Total fertility rate, which represents the number of births of women that would be born to a woman if she were to live to the end of her childbearing years and bear children. Data was collected from WB Database covering 152 countries over a period of nine years (2008-2016). This variable was available for almost the whole selected time period and countries and has been chosen as an independent variable. It is presented in the models and the database as (FER).

\section{Tourism}

This variable is expressed by international tourists (number of arrivals), which is the number of tourists who travel to a country other than that in which they have their usual residence, for a period not exceeding twelve months and whose main purpose in visiting is other than an economic activity. Data was collected from WB Database specifically from (World Tourism Organization), covering 152 countries over a period of nine years (2008-2016). This variable was not available for the whole selected time period and countries and has been chosen as an independent variable. It is presented in the models and the database as (Tourism).

As our data is longitudinal. The two-dimensional variables in our data are:

\section{Country}

Which is the cross sectional variable reflecting 152 countries all over the world; presented in the database as (Country).

\section{Year}

Which this is the time dimension variable and it reflects the period of time from 2008 until 2016; presented in the model and the database as (Year). 


\subsubsection{Dependent variable}

\section{Stability}

Stability is expressed by the Global Peace Index. This index provides a comprehensive analysis of the state of stability for each country in the world. It ranges from 1 for most peaceful to 5 for less peaceful. Data was collected from The Institute for Economics and Peace (IEP) and covers 152 countries over a period of nine years (2008-2016). This variable was available for the whole selected time period and all countries and has been chosen as a dependent variable. It is presented in the models and the database as (GPI).

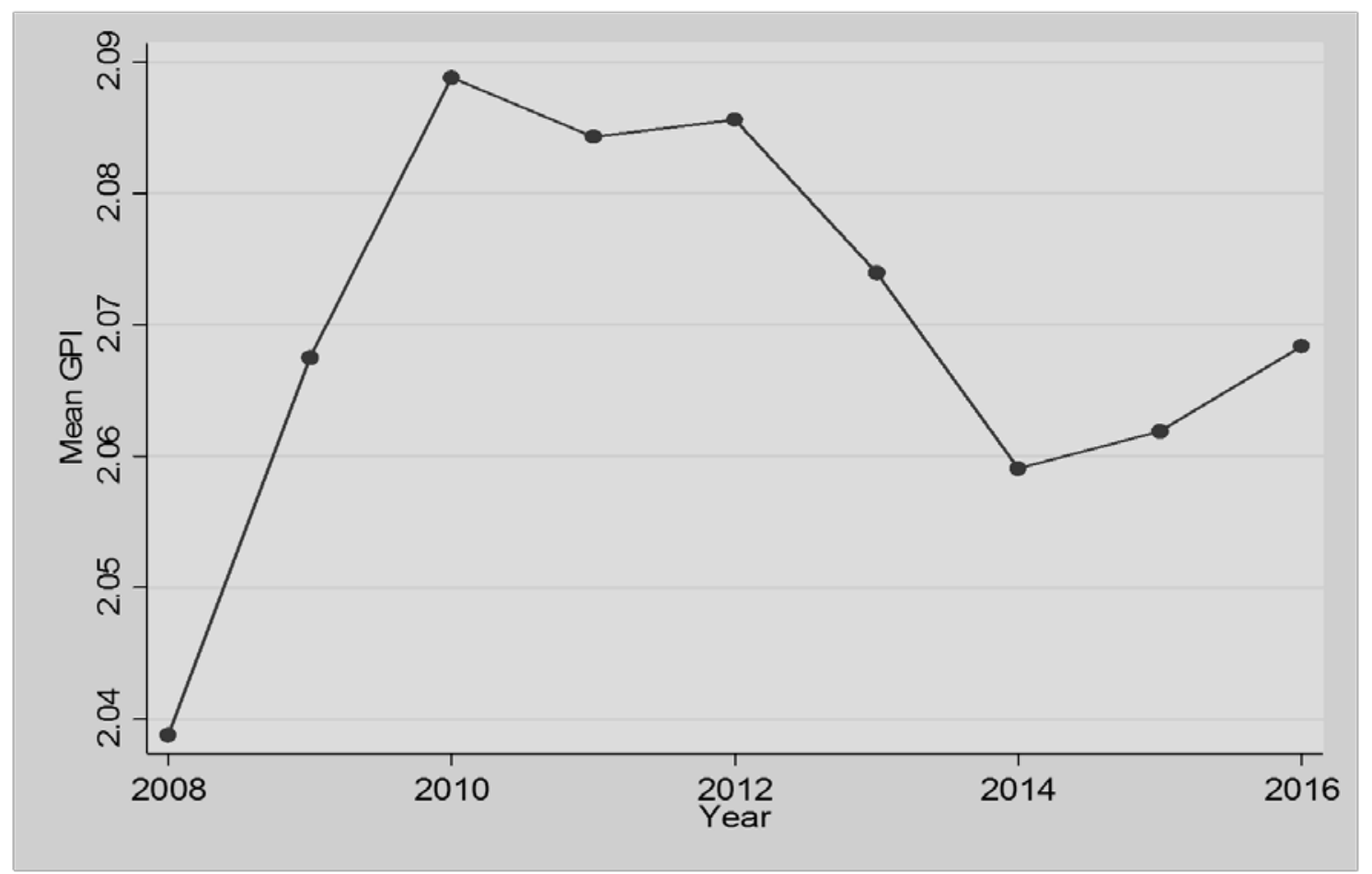

Source: author's illustration

Figure 6: Global Peace Index worldwide sample

The graph above (Figure 6) shows the evolution of world peace and the state of stability from 2008-2016. An instable situation can be seen clearly in 2011 when the political change in the MENA region started. We can also notice an increasing trend of the GPI index in late 2016 which can be explained by the current war and conflict in many regions such as Syria, Yemen and Iraq. 


\subsection{Global Peace Index}

We dedicate this part to a detailed description and explanation of the Global Peace Index. The major challenges humanity is facing at the start of the $21^{\text {th }}$ century are global (energy and food insecurity, climate change, water insecurity and overpopulation, etc.). These challenges are now well documented and supported by many academics. It would be irrational to ignore the devastating effects of these threats on humanity in the future and the present as well. Peace and stability are the essential prerequisite. With stability the world will have more economic growth, social improvement and a stronger effort for conquering environmental problems to ensure sustainability.

We chose the GPI index as our main indicator and proxy for political stability, which measures the peace situation in a country on the national and international level. Contrary to other indicators used by scholars as mentioned in the review part we have chosen to proceed our study using this indicator as it signals the state of stability and absence of violence in a country more accurately. The global index is ranked from 1 to 5 ; the lower the index the more peaceful the country. The data on this index is provided by the IEP since 2007. Our used data set for this index was collected upon request to one of the IEP's office based in Sydney (Economist Intelligence Unit -Office Sydney). The use of the reported data is authorized by IEP license.

The overall score for the GPI index is weighted by 60 percent for internal peace and 40 percent for external peace for each nation covering almost 153 countries in total. This measurement of the absence of violence from both the internal and external level gives an idea on the performance of the political system and the stability in a specific country. Using product moment correlation analysis for multidimensional sub-indicators, the overall score reflects the relationship between different social and economic aspects ranging from transparency and democracy to culture and education (Ali et al., 2012). One of the most important characteristics of this index is that it is the first index to order countries in scale from 1 to 5 according to their peace and stability rate.

More than 20 quantitative as well as qualitative sub-indicators are used to build this composite index as presented in Table 9 Appendix A. The objective is to contribute to the process of scientific comprehensiveness of peace and economic development, (Schippa C., 2011). Conflict and an instable state lead to social and economic damage. 
For example the economic impact of instability according to (Camilla, 2011) in 2016 was almost \$14.3 trillion of world's GDP. So the objective in creating such an index is to contribute in the comparative mechanism of understanding stability over time and help scientific and political community in providing better recommendation and practice for a more stable and peaceful world.

As all different composite indicators, the GPI index has some limitations and criticism that could be summarized by the absence of a strong theoretical model for peace and the randomly weighted method used. Contrarily to (Beck et al., 2000) who tried to give a theoretical concept of conflict, the GPI index is based on variables and a weighted factors approach. These used variables cover basically domestic and international conflict, societal safety and security and militarization, (Tasiran \& Yuan, 2012).

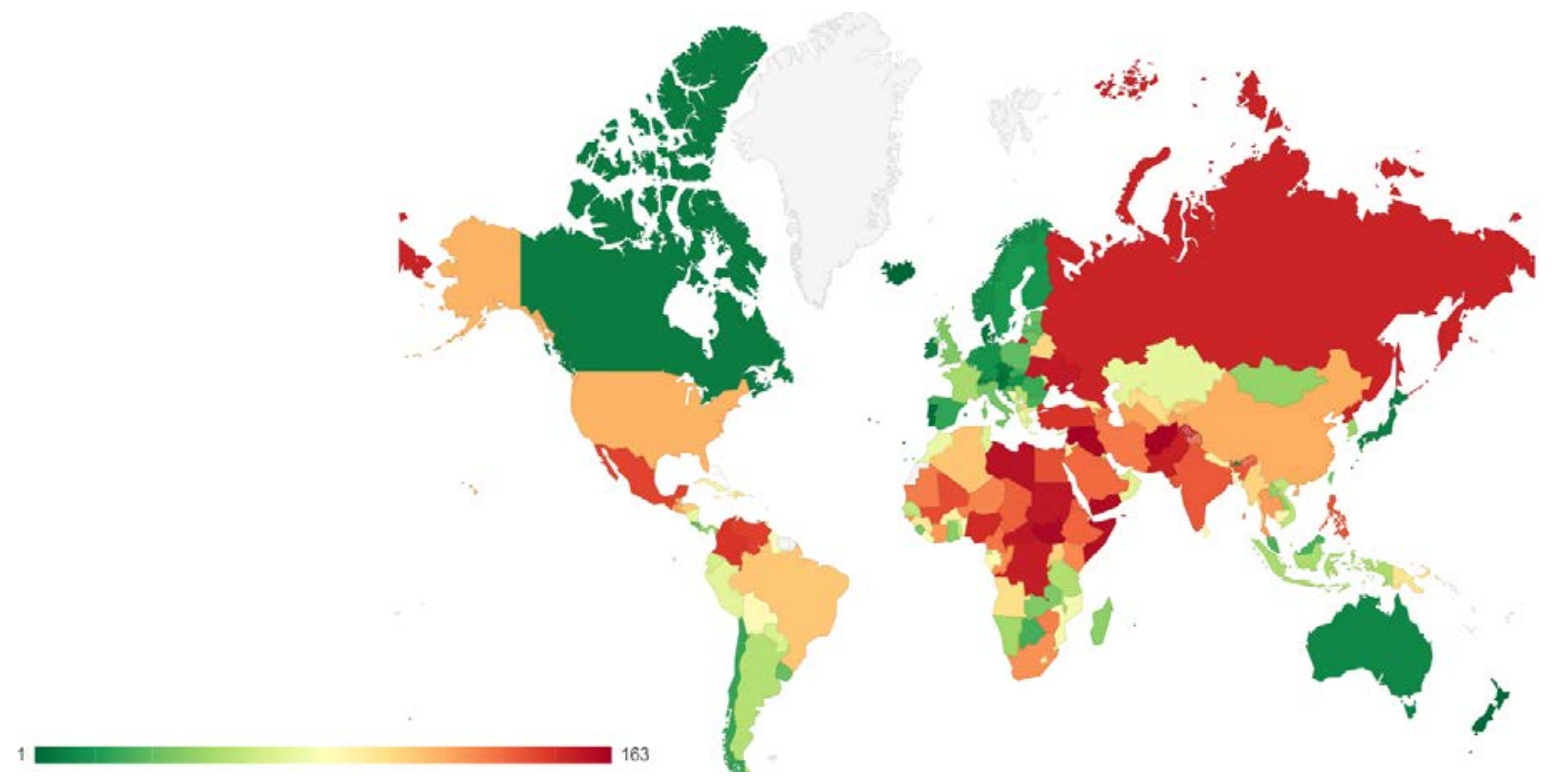

Source: IEP, GLOBAL PEACE INDEX 2017

Figure 7: World map of global peace ranking

Figure 7, shows the level of stability and conflict in each country of the world. The map shows the countries' ranking using the GPI index in 2017.

The red color indicates a high rate of instability and conflict, internally as well as externally. The green color indicates a stable situation. Iceland, New Zealand and Austria are the top listed peaceful and stable countries. Afghanistan, Iraq and Syria are in the bottom of the list with Syria remaining the least peaceful country for the fifth year running. 
Table 3: Data Summary

\begin{tabular}{|c|c|c|c|c|c|}
\hline Variable & Obs & Mean & Std. Dev. & Min & Max \\
\hline GPI & 1368 & 2.069827 & .430324 & 1.089 & 3.605 \\
\hline Country & 1368 & 76.5 & 43.89372 & 1 & 152 \\
\hline Year & 1368 & 2012 & 2.582933 & 2008 & 2016 \\
\hline TNR_lag1 & 1203 & 9.202687 & 12.22802 & 0 & 61.35384 \\
\hline FER_lag1 & 1216 & 2.892031 & 1.490698 & 1.149 & 7.542 \\
\hline Unem_lag1 & 1358 & 8.598608 & 6.181387 & .1 & 37.6 \\
\hline lg_Tourism 1 & 1159 & 14.41134 & 1.750416 & 9.425451 & 18.25169 \\
\hline lg_FDI_lag1 & 1283 & 21.23145 & 2.149484 & 10.9227 & 26.95012 \\
\hline GDPpc_lag1 & 1346 & 1.79804 & 4.430891 & -62.22509 & 24.66657 \\
\hline AR_land_lagl & 1061 & .2511424 & .277539 & .0001024 & 2.134197 \\
\hline CC_lagl & 1366 & -.1030817 & 1.013369 & -1.672876 & 2.446495 \\
\hline EI_lag 1 & 944 & -20.62331 & 145.2841 & -944.8928 & 98.24676 \\
\hline FD_lag1 & 1307 & 82.83856 & 95.44572 & 0 & 581 \\
\hline FD_sq_lag1 & 1307 & 15965.14 & 35485.65 & 0 & 337561 \\
\hline R_Law_lag1 & 1367 & -.1155691 & .993998 & -2.178493 & 2.100273 \\
\hline $\mathrm{V} \_\mathrm{ACC} \_$lag 1 & 1367 & -.1391511 & .9704558 & -2.259159 & 1.737975 \\
\hline
\end{tabular}

\section{Source: author's illustration}

Table 3 gives a summary of the used variables in our study. It shows the average of each variable and the number of observation. We see that the number of observations will be reduced in the sample, in particular because of some missing data from some countries and basically because of data on energy imports (EI). 
Also some control variables were excluded due to their presence in the GPI index calculation; in order to reduce endogeneity problems in our regression analysis. We see in this Table 3 that average energy import worldwide is -20.62 which indicate that world most countries are relying on importing energy for their economic activity. The average food deficit in the world during the time spam between 2008 and 2016 is 82.83 indicating haw grave is the food situation in the world. The world mean value of the three WGI used in this study shows a negative sign which again point high corruption level, absence of the enforcement of law in many countries and bad intuitional quality. A summary of the detailed statistical description can be found in Table 7 in Appendix A. 


\section{4- Results and Discussion}

In this part we are going to present our regression results, which as shown by Tables 5a and $5 b$ below. Here all estimations from the model (A to D) are a result of the fixed effect model. The decisions are based on the result of Hausman-Test.

Table 4.a: Regression results of fixed effect Model (part1)

\begin{tabular}{|c|c|c|c|c|}
\hline \multicolumn{5}{|c|}{ Dependent Variable: $\quad$ GPI $_{i t}$} \\
\hline Variables & Model_A & Model_B & Model_C & Model_D \\
\hline \multirow{3}{*}{$\operatorname{GDPpc}_{i, t-1}$} & $-0.0019721 * *$ & $-0.00196465^{* *}$ & $-0.00177858 * *$ & -0.00167724 \\
\hline & $(-2.22)$ & $(-2.20)$ & $(-2.06)$ & $(-1.93)$ \\
\hline & 0.070779 & 0.0718161 & 0.06213171 & 0.03189194 \\
\hline \multirow[t]{2}{*}{$\mathrm{FER}_{i, t-1}$} & $(1.00)$ & $(0.95)$ & $(0.84)$ & $(0.44)$ \\
\hline & 0.00077215 & 0.00078198 & 0.00076396 & 0.00043375 \\
\hline \multirow[t]{2}{*}{$\mathrm{TNR}_{i, t-1}$} & $(0.50)$ & $(0.52)$ & $(0.52)$ & $(0.29)$ \\
\hline & 0.00437132 & 0.00436492 & 0.00428351 & 0.00307077 \\
\hline \multirow[t]{2}{*}{ Unem $_{i, t-1}$} & $(1.48)$ & ( 1.49$)$ & $(1.48)$ & $(1.20)$ \\
\hline & $-0.09531293 * *$ & $-0.09582055^{* *}$ & $-0.10276681^{* *}$ & $-0.09233029 * *$ \\
\hline \multirow[t]{2}{*}{$\lg \_$Tourism $_{\mathrm{t}-1}$} & $(-2.57)$ & $(-2.39)$ & $(-2.57)$ & $(-2.24)$ \\
\hline & 0.31994478 & 0.32128209 & $0.34635793 * *$ & $0.3571869 * *$ \\
\hline \multirow[t]{2}{*}{ AR_land ${ }_{i, t-1}$} & $(1.77)$ & $(1.85)$ & $(2.08)$ & $(2.24)$ \\
\hline & $-0.15426557 * * *$ & $-0.15431901 * * *$ & $-0.14751106^{* * *}$ & -0.0983909 \\
\hline \multirow[t]{2}{*}{$\mathrm{CC}_{i, t-1}$} & $(-2.71)$ & $(-2.70)$ & $(-2.67)$ & $(-1.66)$ \\
\hline & -0.00280259 & -0.00287517 & -0.00242212 & -0.00274237 \\
\hline \multirow[t]{2}{*}{$\lg \_$FDI $_{i, t-1}$} & $(-0.47)$ & $(-0.48)$ & $(-0.41)$ & $(-0.48)$ \\
\hline & $0.00037037 * *$ & $0.00036967 * *$ & $0.00037324 * *$ & $0.00037621 * *$ \\
\hline \multirow[t]{2}{*}{$\mathrm{EI}_{i, t-1}$} & $(2.46)$ & $(2.49)$ & $(2.44)$ & $(2.57)$ \\
\hline & & -0.0000291 & -0.00118932 & -0.00137904 \\
\hline \multirow[t]{2}{*}{$\mathrm{FD}_{i, t-1}$} & & $(-0.06)$ & $(-1.59)$ & $(-1.85)$ \\
\hline & & & $3.24 \mathrm{E}-03 * *$ & $3.62 \mathrm{E}-03 * *$ \\
\hline \multirow[t]{2}{*}{ FD_sq ${ }_{i, t-1}$} & & & $(2.09)$ & $(2.32)$ \\
\hline & & & & $-0.17367846^{* *}$ \\
\hline \multirow[t]{2}{*}{$\mathrm{R} \_L a w_{i, t-1}$} & & & & $(-2.30)$ \\
\hline & $3.2085 * * *$ & $3.2167 * * *$ & $3.3695 * * *$ & $3.3176 * * *$ \\
\hline Constant & $(4.73)$ & $(4.50)$ & (4.68) & $(4.48)$ \\
\hline
\end{tabular}


Table 4.b: Regression results of fixed effect Model (part2)

\begin{tabular}{|c|c|c|c|c|}
\hline Observations(N) & 788 & 788 & 788 & 788 \\
\hline Number of Countries & 121 & 121 & 121 & 121 \\
\hline F_statistic & 3.424 & 3.250 & 3.139 & 3.259 \\
\hline $\mathrm{R}^{2}$ (within) & 0.16 & 0.16 & 0.17 & 0.19 \\
\hline Hausman_Test & $\mathrm{FE}^{* * *}$ & $\mathrm{FE}^{* * *}$ & $\mathrm{FE}^{* * *}$ & $\mathrm{FE}^{* * *}$ \\
\hline testparm i.Year & 0.6151 & 0.5294 & 0.5899 & 0.5149 \\
\hline$(\text { Prob }>F)^{\mathbf{a}}$ & $(0.74)$ & $(0.85)$ & $(0.77)$ & $(0.87)$ \\
\hline Wald test & 0.0000 & 0.0000 & 0.0000 & 0.0000 \\
\hline$\left(\operatorname{Prob}>X^{2}\right)^{\mathbf{b}}$ & $(15857.70)$ & $(23061.72)$ & $(22410.93)$ & $(28406.71)$ \\
\hline \multicolumn{5}{|c|}{$\begin{array}{l}* * * p<0.01, \text { denotes significance at the } 1 \% \text { level } \\
* * \mathrm{p}<0.05 \text {, denotes significance at the } 5 \% \text { level } \\
* \mathrm{p}<0.1, \text { denotes significance at the } 10 \% \text { level }\end{array}$} \\
\hline \multicolumn{5}{|c|}{$\begin{array}{l}\text { t-statistics for the variables in parenthesis. It's corrected using heteroscedasticity-consistent Robust } \\
\text { a The testparm i. Year is conducted to see if the time fixed effect is needed or not, where the null } \\
\text { hypothesis implies presence of time fixed effect. } \\
\text { b The Wald test is a test for heteroscedasticity. }\end{array}$} \\
\hline
\end{tabular}

Source: author's illustration

The estimations also include Heteroscedasticity robust standard errors. To allow for a comparison between the different models we have fixed the number of observations to 788 observations per regression as shown in table $4 \mathrm{~b}$. After controlling for an equal number of observations and due to the missing data as explained before our sample size in each regression has been further reduced to 121 countries.

In the first model (A) shown in Table 4a we have included the control variables following the literature discussed in part two and the energy security indicator. Some control variables were excluded from the list as they are already represented in the calculation of the dependent variable GPI index. One example of these excluded variables is the military expenditure as a share of GDP. 
Our explained variable is a composite of some other indicators as presented in previous parts of this study. In order to decrease the chance of the endogeneity problem we have selected our control variables in a manner, that they are not highly correlated or represented in the GPI index.

So in the first Model (A) we aim to test one part of our hypothesis. The hypothesis is whether there exists an effect of energy security on stability or not and which sign or direction of relationship there is. As presented in Table 4a, second column, the variables GDPpc, Tourism and EI are significant at the 5\% level also with the expected sign. This implies that more economic growth leads to a more stable state in a country. Higher GDP per capita and a better economic situation will have a positive impact on country stability. This result was also proven by (Uddin et al., 2017). The Tourism variable, which represents the number of tourists received by a country also indicates that tourism is positively affecting stability. The more tourists a country receives, the more the cultural gap and fractionalization is decreasing. Tourism also helps bringing people together and improves social interaction. The positive effect of tourism has been proven by (Farmaki, 2017) as well.

Our main variable, which is the energy imports, in this work reflect the energy insecurity state in a country. The energy variable shows a negative impact on stability, which denotes that more energy insecurity in a country will affect stability in negative way. According to our expectation this result is in line with the theoretical design of this work. More energy imported by a country over time translates into more energy insecurity. A high import rate can indicate the lack of a good strategic energy plan in a country. A country's economy based on large energy import shares will have an instable economic state and an instable political system. Therefore more conflict could take place. This is due to the instable supply, price fluctuations for energy and the growing demand on this commodity over time.

The variable 'Control of corruption' is statistically significant at the $1 \%$ level. It also shows a positive relationship with the dependent variable. This is one of the expected results as controlling corruption in a country will lead to more growth and better planning in terms of energy which will promote more stability. In the other way around this result suggests that more corruption leads to more instability. The negative effect of corruption was also proven in previous studies. The rest of the control variables like FER, TNR, Uemp and FDI are not statistically significant but accompanied by the expected sign. 
In the second regression model (B), Table 4a the food security indicator was included along with all the previously mentioned variables. In this model the food security is reflected by the variable food deficit, expressed by the kilocalorie deficit of food per person per day in a country. This variable presents the state of food insecurity. The significance results from model $\mathrm{A}$ to $\mathrm{B}$ have not changed in all variables after adding the food security proxy variable (FD) in our model.

The result shows an unexpected sign and an insignificant effect of the latest mentioned variable. This surprising result was not in line with the tested hypothesis. This implies that a further investigation is needed. So we decided to include a squared term of the FD variable in order to inspect food insecurity at a more intense level.

The model $\mathrm{C}$ illustrates the result after counting for a higher level of food insecurity. Comparing to (A) and (B) in Table 4a, the control variable AR_land in the regression result of model $\mathrm{C}$ shows a significant result at the 5\% level with the expected sign. The negative relationship between stability and arable land was also illustrated in the literature, for example by (Boone, 2017). The conflict over land has often been discussed in the literature. Because land is one crucial production input in most developing countries that are mainly based on agriculture. Developing and under developed countries have an economy based on the agricultural sector and land scarcity will bring about more instability. Land is also one determinant factor to ensure food security

In the specification model (C) Table 4a, the control variables (GDPpc) and (lg_Tourism) kept the same 5\% significance level as well as the expected sign. The variable (CC) also remains at the $1 \%$ significance level with a negative sign. Our new integrated main variable, which is the squared term of food deficit, shows a positive sign with a significance level of $5 \%$. This variable as explained before is used to test the effect of higher food insecurity on stability. The results are perfectly as expected showing that the food insecurity will negatively affect stability but at a higher level of insecurity. Improving the food security situation in a country will help mobilizing peace and keeping stability.

We added a supplementary inspection in model (D) where a variable from WGI reflecting the institutional quality was included. In regression (D) we control for all variables from the previous specification including FS and ES indicators along with the variable Rule of Law as presented in the fifth column in Table $4 \mathrm{a}$. 
The main change from $\mathrm{A}$ to $\mathrm{D}$ after controlling for institutional quality in the regression is that the variable GDPpc and CC have lost their significance power but still come with the same expected sign.

The new included variable in this specification is significant at the $5 \%$ level with the expect sign. This entails that the enforcement of law and the protection of property rights bring about a stable state and reduce the probability for the occurrence of conflict. The effect of institutional quality on political stability does not seem a surprising result as good institution and better performance of the juridical system will lead to more economic development and lower corruption. The indirect effect of a good institutional quality will have a positive impact on stability.

Table 5: Last Regression results of fixed effect Model

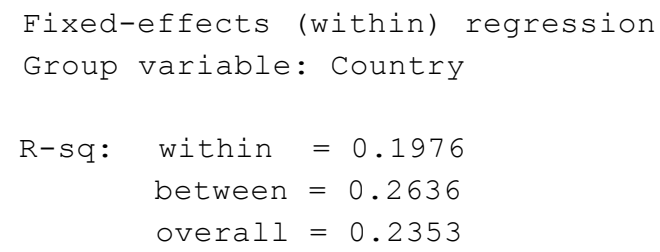

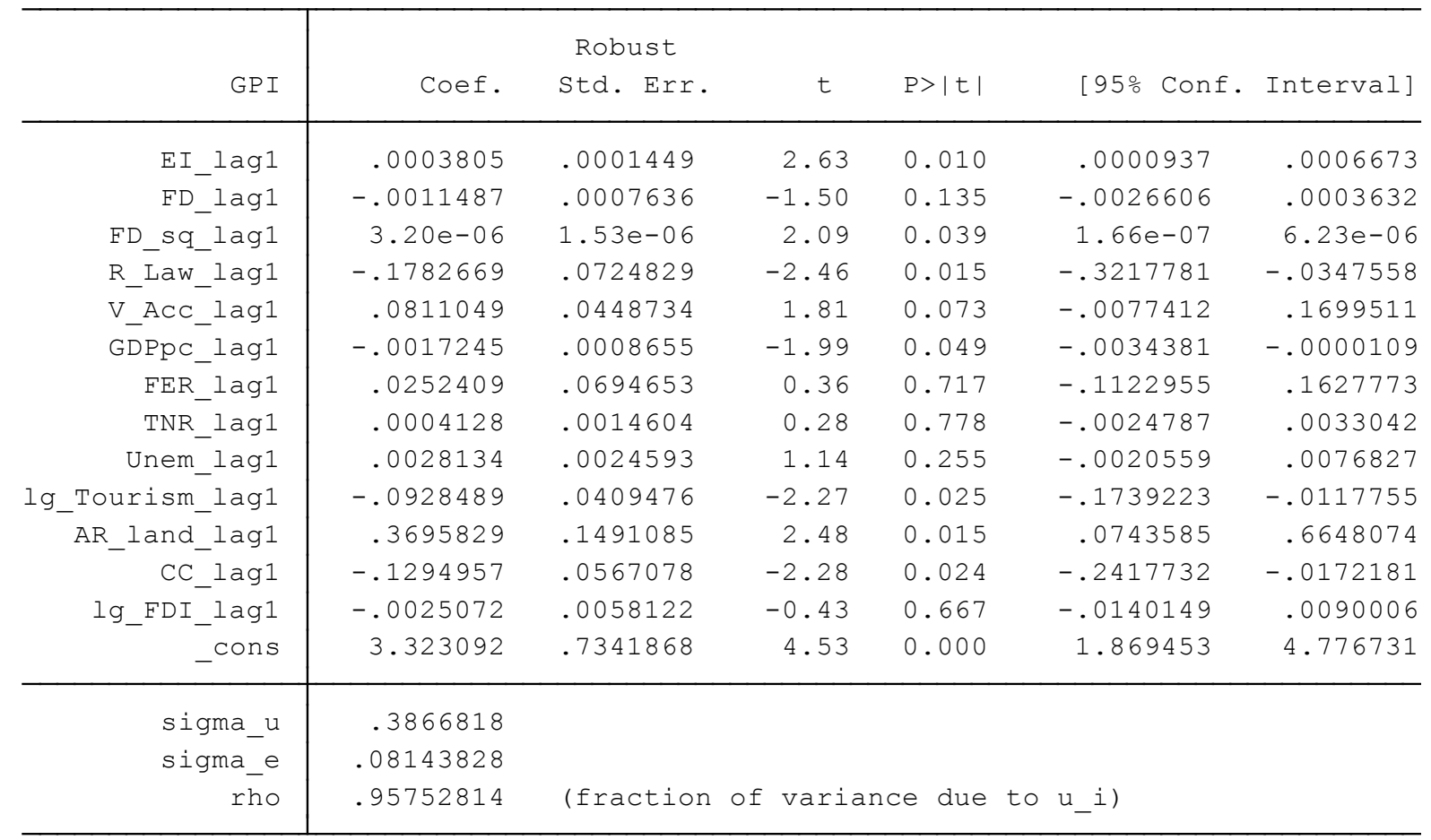


The regression output from Table 5 shows the last model in our regression result. In this regression we have included all the control variables with the main tested variables as well. An additional world governance indicator, (voice and accountability) is included in the last model. This indicator reflects the government quality and level of transparency in a country.

The results show that the (GDPpc) variable has regained its significance power with the same expected sign. The control variables GDPpc, TOURISM, AR_land, CC, have the expected sign with the 5\% significance level. This implies the same previous interpretation of the results. Tourism and enforcement of law help to bring about more peace and stability at the $5 \%$ significance level. Concerning the main variables we clearly see that the variable (EI) is still significant at the $1 \%$ level with the expected sign, too. Beside that (FD_sq) and (R_law) show a positive sign with a significance level of $5 \%$. Security of property rights and high institutional quality in countries also have a significant positive effect on the stability of a political system.

Taking into account, model C, D, Table 4a, and the last result, Table 5, after adding all the variables of interest we see that the energy and food insecurity indicators show a robust significant result with an expected sign towards stability. These results of fixed effect of panel regressions from table 4 and 5 show a negative effect of fertility rate, resource rents and unemployment on stability, which is not significant though. Other destabilizing factors that are significant according to the results are arable land scarcity, corruption and the two main factors in our analysis, food and energy insecurity.

The significant result for food insecurity was gained after controlling for a higher level of food deficit. This suggests that energy and food security play an important role in government stability. And in particular, at a certain level of food insecurity the risk of having a conflict state is higher. This led us to further investigate the change of sign of the variable food deficit in our last regression result. We started by assuming the existence of an inverted u-Shape between GPI and the FD variables. Therefore we have executed a statistical test using STATA software following the work of (Lind and Mehlum, 2010). We found a nonsignificant result for the existence of an inverted $u$-shape. 
Our last result model (5) has the form as follows:

$G P I_{i t}=\alpha+\beta_{1} * \mathrm{EI}_{i, t-1+} \beta_{2} * \mathrm{FD}_{i, t-1+} \beta_{3 *}(\mathrm{FD} * \mathrm{FD})_{i, t-1+} \beta_{4} * \mathrm{R} \_L a w_{i, t-1+} \beta_{5} * \mathrm{~V}_{-} \operatorname{Acc}_{i, t-1+} \beta_{6^{*}}$

$\mathrm{Z}_{i, t-1+U i+} \theta_{\mathrm{t}}+\mathrm{e} i, t-1$

Where $\mathrm{i}=1, \ldots, \mathrm{N}$ ( $\mathrm{N}$ denotes the total number of countries); $\mathrm{t}=1, \ldots, \mathrm{T}-1$ ( $\mathrm{T}$ denotes the total number of years in lagged format ); GPI $\mathrm{it}_{\mathrm{it}}$ denotes Stability in country $\mathrm{i}$ in year $\mathrm{t} ; \mathrm{Z}_{\mathrm{i}, \mathrm{t}-1}$ is the vector of endogenous explanatory variables for country $i$ in year $t-1$. The error terms $e_{i, t-1}$ are assumed to be independent and identically distributed.

Summarizing the results by the equation (5), the sign of $\beta_{1}$ is positive with a significance level of $1 \%$. This implies that more energy insecurity will increase conflict in a country as the GPI index has a scale from 1 (most stable state) to 5 (most instable state).

The parameter $\beta_{2}$ in this equation was negative, which was unexpected and not significant as well. After further investigating the discussed hypothesis of the negative effect of energy insecurity on stability we can see that the interaction term of food deficit in squared term has a coefficient $\beta_{3}$, which is positive and significant at the $5 \%$ level. The interpretation in this case would be that at a higher level of food insecurity the negative impact of food insecurity on stability is significant.

From the two WGI variables that are included in this last regression the Rule of law indicator has a coefficient $\beta_{4}$, which is at the $5 \%$ level of significance and negatively correlated with the dependent variable. This suggests that better performance of intuitions and enforcement of law will ensure peace and stability. The last remaining indicator (V_Acc) was not significant. In this last regression, too, we have 788 observations as in the previous one and a reduced sample of 121 countries included from a total of 152 in the database.

As we have seen in our result that the effect of more intensified situation of food insecurity has shown a negative effect on stability. The tested inverted $u$-shape relationship between the two variables food deficit and food deficit squared term has been identified as not significant. So we have decided to calculate the marginal effect of FD variable on stability indicator in our last regression model as presented in equation number (5). 
The marginal effect of the food deficit variable on the GPI index will be calculated by taking the derivative of the conditional mean function of the dependent variable GPI with respect to the FD variable at a different level.

The marginal effect of food deficit on Stability

$\frac{\partial\left(G P L_{i t}\right)}{\partial\left(F D_{i, t-1}\right)}=\beta_{2}+\beta_{3} *\left(F D_{i, t-1}\right)$

According to the estimation result from Table 6 of our last model (5), we compute the slope for stability on food deficit at different values going from 300 (Kcal/person/day) to 1000 (Kcal/person/day) of food deficit as presented in equation number (6).

We are aiming here to compute the instant rate of change of GPI index in response to different food insecurity levels while maintaining the other variables constant. The results show that after a threshold level of 800 in food deficit, the final effect of food insecurity on stability becomes statistically insignificant. The level of 800 deficit in food is significant at $5 \%$ level with the expected sign. The positive sign here of food insecurity indicates that this variable contributes in an increasing the level of GPI index which translates into a more instable state according to GPI scores. GPI scores again as a reminder are starting from 1 more stable and peaceful state to 5 which is instable. In more accurate explanation, food insecurity at the levels beyond $800 \mathrm{Kcal} /$ person/day deficit is a significant destabilizing factor.

Table 6: Average marginal effect of food deficit

\begin{tabular}{|c|c|c|c|c|}
\hline $\begin{array}{c}\text { Food Deficit } \\
\text { previous year) }\end{array}$ & d(Stability)/d(Food Deficit (previous year)) & $\begin{array}{c}\text { Delta-Method } \\
\text { Std. Err. }\end{array}$ & $\mathbf{Z}$ & p-value \\
\hline $\mathbf{3 0 0}$ & 1.801 & 0.172 & 10.490 & 0.000 \\
\hline $\mathbf{4 0 0}$ & 1.687 & 0.248 & 6.800 & 0.000 \\
\hline $\mathbf{5 0 0}$ & 1.572 & 0.325 & 4.840 & 0.000 \\
\hline $\mathbf{6 0 0}$ & 1.457 & 0.401 & 3.640 & 0.000 \\
\hline $\mathbf{7 0 0}$ & 1.342 & 0.477 & 2.810 & 0.005 \\
\hline $\mathbf{8 0 0}$ & 1.227 & 0.554 & 2.220 & 0.027 \\
\hline $\mathbf{9 0 0}$ & 1.112 & 0.630 & 1.770 & 0.077 \\
\hline $\mathbf{1 0 0 0}$ & 0.997 & 0.706 & 1.410 & 0.158 \\
\hline
\end{tabular}

Source: author's illustration 
Table 6 shows the average marginal effects of food deficit on stability at different levels. For example, with food deficit at the level of $800 \mathrm{Kcal} /$ person/day, a one-unit increase in the food deficit leads to a reduction of Global peace index by 1, 22 standard deviation. In this case, the point estimate implies that a 1 standard deviation increase in food deficit last year decreases stability in the current year by about 1.2 standard deviations.

Figure $8 \mathrm{a}$ and $8 \mathrm{~b}$ are a graphical presentation of Table 6. It shows Marginal effects of food deficit (previous period) on stability at different levels of the previous period of FD reporting the $95 \%$ confidence intervals around the marginal effects. The middle line shows the marginal effects and the blue area are confidence intervals at 95\% level. Calculations are based on Model (5), the results show that the marginal negative effects of food deficit on political stability are statistically significant at the level of $800 \mathrm{kcal} /$ person/day.

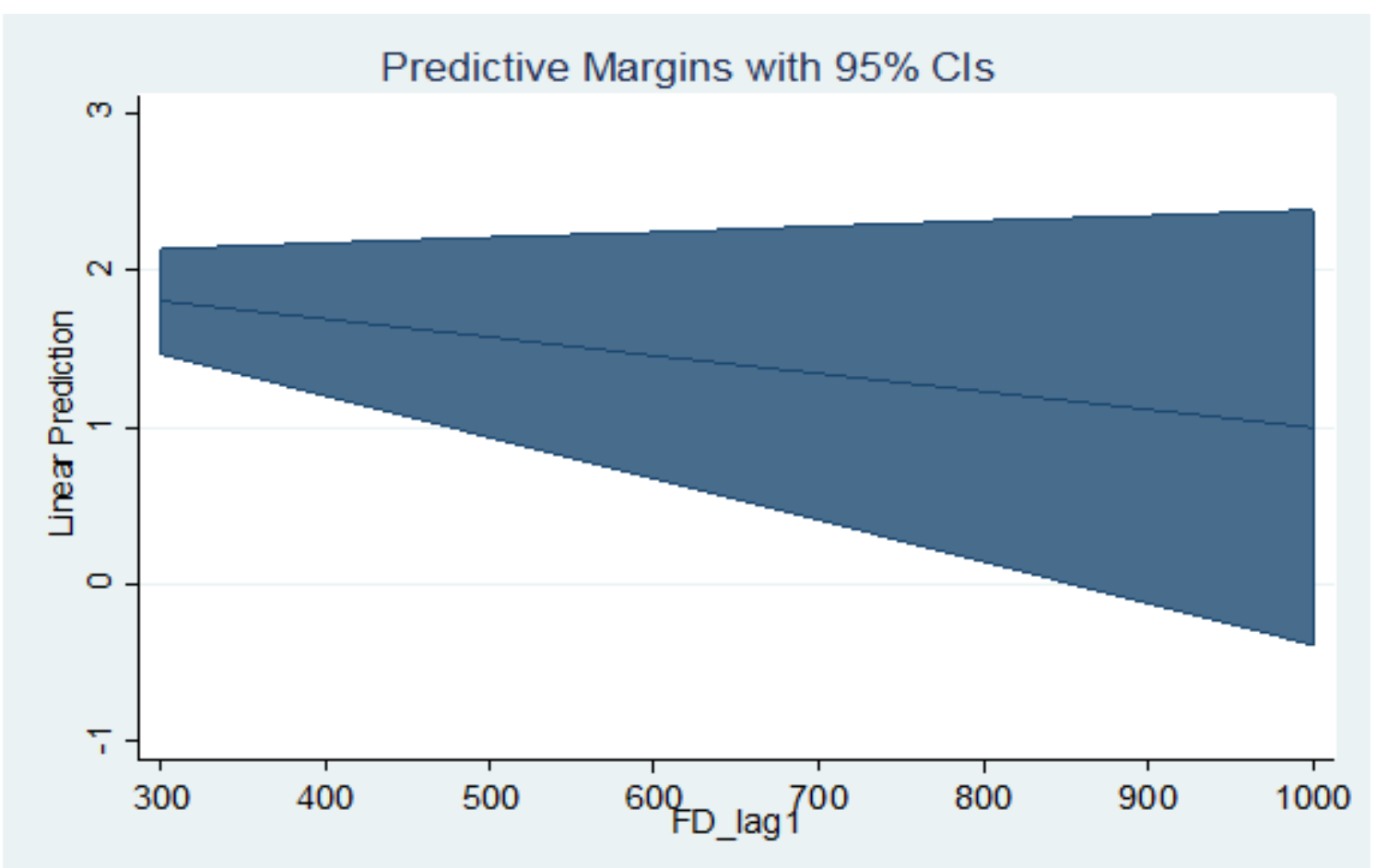

Source: author's illustration: STATA Software

Figure 8.a: Marginal effects of food deficit 


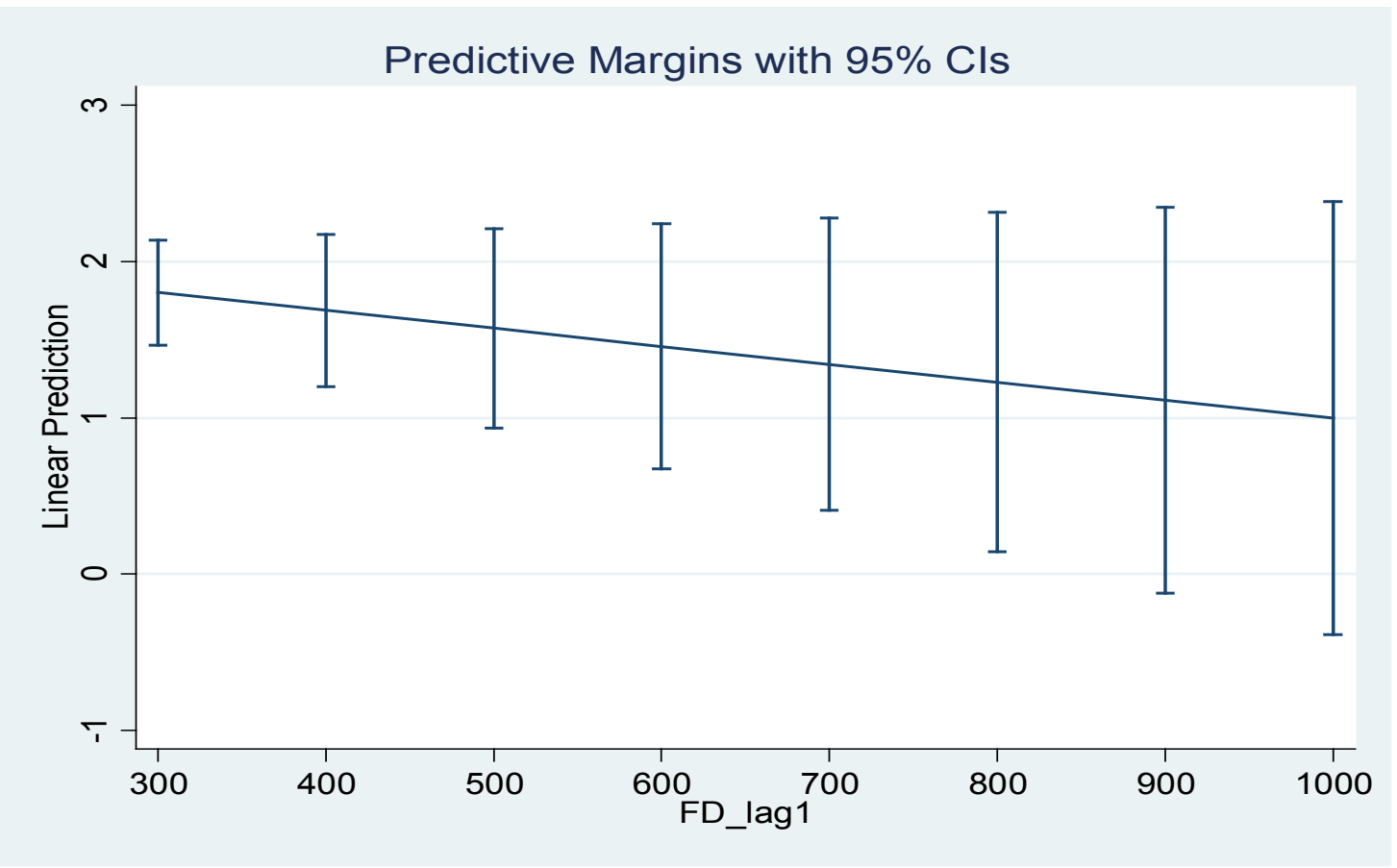

Source: author's illustration: STATA Software

Figure 8.b: Marginal effects of food deficit

The effects of energy insecurity on stability are significantly negative within a country. The squared term of food deficit is positive and highly statistically significant in all last three regression steps since its inclusion. This implies that the effect of food insecurity in negative and its marginal effect also is highly significant and negative especially from a threshold of $800 \mathrm{Kcal} /$ person/day deficit of food per day within a country. 


\section{5- Conclusion}

This study has used a worldwide data set on the GPI index and other variables spanning a time frame from 2008 to 2016 to assess the effect of food and energy security on stability in countries. Using a fixed effect model on panel data, the result shows a robust significant negative effect of energy and food insecurity on stability. A further investigation was conducted to include institutional quality which has shown a significant impact on stability as well. Improving food security can be realized through many measures as ensuring sustainable agricultural policy and enhancing the balance of import and export.

A good institutional quality is also required to hedge against the price volatility of this commodity. Energy security, too, as proven in this work plays an important role in keeping stability within a country. A green and sustainable strategic energy plan in a country might help boosting economic growth, reducing energy dependency and bringing a more stable economic and political state to a country. Nevertheless the necessity of energy is crucial but it is also highly required to move on to the next step of clean energy, as the effects of climate change are reducing arable land and increasing desertification. These factors negatively affect the food security objective. One major source of climate change is the $\mathrm{CO}_{2}$ emission generated by traditional energy sources, especially with the increased industrialization waves to date.

Food and energy security are a situation whereby a countries strategic plan is able to cover the need in terms of food and energy of its population in a continued way. These two concepts are in line with the Millennium Development Goals. Specifically, ensuring food security at the country level by reducing the gap between per capita calorie supply and per capita dietary energy requirements requires addressing a number of issues. These include voluntary resettlement of the rural population, stabilizing the developing countries' population, etc.

Maystadt, (2014), proved that food security matters for the transition in Arab countries, arguing that price volatility and food availability in these countries could trace the future of their political transition. Helping to understand conflict management channels in the world will call for more peace and stability. This study contributed to the understanding process and how to ensure stability within a country. 
Energy and food have been identified here as important in terms of political stability as well as their economic importance. Technological exchange between countries concerning the best clean and sustainable energy will help reaching the goal; as well as exchanging agricultural practices and new methods of sustainable use of resources will bring more security in terms of food and stability. What is also important is fighting corruption and enhancing institutional quality in countries. Biofuel production and climate change seems to need deeps investigation on stability in the future. The importance of these two mentioned concepts comes from their interrelation in terms of energy and food. Biofuel production has been proves in some studies to have a negative effect on food security through land use completion with conventional food crops. On the other hand Biofuel also helps reaching the energy security objective in the long run. The climate change also might affect both energy and food security by its effect resulting in desertification and drought. So climate change could negatively affect food security again by reducing arable land and resource on water, as well as the energy security by decreasing hydroelectric production because of drought. These two intersection points between food and energy need further investigation on their effect on stability. 


\section{Acknowledgment}

Ich möchte mich an dieser Stelle von ganzem Herzen bei meinen beiden Betreuern Herr Prof. Dr. Mohammad Reza Farzanegan und Herr Sven Fischer bedanken. Ebenso Frau Dr. Regine Reck und Prof. Dr. Michael Kirk für Ihre Unterstützung und Hilfe vielen Dank. Ohne Sie und Ihre sowohl fachliche als auch menschliche Betreuung wären dieses Studium und diese Masterarbeit nicht möglich gewesen. Auch den übrigen Angehörigen des Instituts für Economics and Peace (Economist Intelligence Unit - Office Sydney), welche mir stets zur Seite standen, bin ich zu tiefem Dank verpflichtet. Nicht vergessen möchte ich an dieser Stelle auch meine Kommilitonen und Kommilitoninnen, die mich während dieses Lebensabschnittes begleitet und unterstützt haben. Während allen Phasen des Studiums habe ich neue Freunde gefunden, welche auch außerhalb fachlicher Fragen immer ein offenes Ohr hatten. Besonders erwähnt werden sollen auch die Mitglieder des Fachschaftsrates, mit denen ich viel gemeinsame Zeit verbracht habe, sowohl in der Rolle als Mitglied als auch in der Rolle als Freund. Abschließend möchte ich den wichtigsten Menschen danken, meiner Familie und meinen Freunden in Tunesien und Deutschland. Ihr wart stets an meiner Seite und habt mir erst dadurch dieses Studium ermöglicht.

\section{Vielen Dank!}




\section{References}

Aftab Hussain Tabassam, Shujahat Haider Hashmi, Faiz Ur Rehman, 2016. Nexus between Political Instability and Economic Growth in Pakistan. 3rd International Conference on New Challenges in Management and Organization: Organization and Leadership, Dubai, UAE. Procedia - Social and Behavioral Sciences 230 - 325 - 334.

Alejandro Corvalan, Miguel Vargas, 2015. Segregation and conflict: An empirical analysis. Journal of Development Economics 116 - 212-222.

Ali C. Tasiran and Lin Quao-Yuan, 2012. Factors to theorise the Global Peace Index, Middlesex University.

Alexeev, M., Conrad, R., 2011. The natural resource curse and economic transition, Economic Systems, Vol. 35, pp. 445-461, Elsevier Science Publishers B.V., North-Holland.

Alvaro Aguirre, 2016. The risk of civil conflicts as a determinant of political institutions. European Journal of Political Economy 42 - 36-59.

Anna Farmaki, 2017. The tourism and peace nexus. Tourism Management 59 - 528e540.

Ang, B.W., W.L. Choong, and T.S. Ng. "Energy security: Definitions, dimensions and indexes. „Renewable and Sustainable Energy Reviews 42 (2015): 1077-1093.

Askjellerud, S. 2003. The tourist: A messenger of peace? Annals of Tourism Research, 30(3), $741 \mathrm{e} 744$.

Assaad, R. \& Roudi-Fahimi, F. 2007. Youth in the Middle East and North Africa: demographic opportunity or challenge? Population Reference Bureau's Policy Brief, Washington, DC.

Badi H. Baltagi, Qu. Feng, and Chihwa Kao, 2012. A Lagrange Multiplier Test for Cross-sectional Dependence in a Fixed Effects Panel Data Model. Center for Policy Research.

Beck, N., G. King and L. Zeng, 2000. Improving quantitative studies of international conflict: A conjecture, American Political Science, Vol. 94, and No.1.

Bert Kruyt, D.P.vanVuuren, H.J.M.deVries, H.Groenenberg, 2009. Indicators for energy security. Energy Policy 37-2166-2181.

Bjorvatn, K., Farzanegan, M.R., Schneider, F., 2013. Resource curse and power balance: evidence from Iran. Review of Middle East Economics and Finance 9, 133-158.

Bloom, D. E. \& Williamson, J. G., 1998. Demographic transitions and economic miracles in emerging Asia. World Bank Economic Review, 12(3), 419-55.

Bloom, D. E., Canning, D. and Malaney, P. N., 2000. Demographic change and economic growth in Asia. Population and Development Review, 26, 257-290 (Suppl.).

Brunnschweiler, C.N., 2008. Cursing the Blessings? Natural Resource Abundance, Institutions, and Economic Growth, World Development, Vol. 36, No. 3, pp. 399-419, Elsevier Science Publishers B.V., North-Holland.

Brunnschweiler, C.N., Bulte, E.H., 2008. The resource curse revisited and revised: A tale of paradoxes and red herrings, Journal of Environmental Economics and Management, Vol. 55, pp. 248-264, Elsevier Science Publishers B.V., North-Holland. 
Calderwood, 2011. The National News. Link: https://www.thenational.ae/world/mena/kuwait-giveseach-citizen-dh13-000-and-free-food-1.382698.

Camilla Schippa, 2011. The Global Peace Index. F. M. Go et al. (eds.), International Place Branding Yearbook 2011 CHAPTER 10.

Catherine Boone, 2017. Sons of the Soil Conflict in Africa: Institutional Determinants of Ethnic Conflict Over Land. World Development Vol. 96, pp. 276-293.

Causevic, S., 2010. Tourism which erases borders: An introspection into Bosnia and Herzegovina. In Tourism, progress and peace (pp. 48e64).

Claude Ake, 1975. A Definition of Political Stability. Comparative Politics, Ph.D. Programs in Political Science, City University of New York. Comparative Politics, Vol. 7, spp. 271-283.

Collier, P. and Hoeffler, A., 2004. Greed and grievance in civil war. Oxford Economic Papers.

Collier.P. and Hoeffler, A, 1998 .On the Economic Causes of Civil War. Oxford Economic.

Dani Rodrik, 1997. The Globalization Paradox. Has Globalization Gone Too Far Challenge Vol 41 No 2 .

David and Bar-Tal, D., 2009. A socio-psychological conception of collective identity: The case of national identity. Personality and Social Psychology Review, 13, 354-379.

Dirk Bezemer and Richard Jong-A-Pin, 2013. Democracy, globalization and ethnic violence. Journal of Comparative Economics, vol. 41, issue 1, 108-12.

Ellen Messer and Marc. J. Cohen, 2006. Conflict, Food Insecurity, and Globalization. Food Construction and Nutrition Division. FCND Discussion Paper 206.

Erik O. Kimbrougha, Kevin Laughrena, Roman Sheremet, 2017. War and conflict in economics: Theories, applications, and recent trends. Journal of Economic Behavior and Organization.

FAO, 2008c. Introduction to the concepts of food security, EC-FAO program "Food security: information for action", Rome, $4 \mathrm{p}$.

FAO, 2009. The State of Food and Agriculture. Food and Agriculture Organization of the United Nations, Rome.

FAO, IFAD and WFP. 2015. The State of Food Insecurity in the World. Meeting the 2015 international hunger targets: taking stock of uneven progress. Rome.

FAO, Rome (Italy) The state of food and agriculture 1995. (FAO Agriculture Series, no. 28).

Felix Haass and Martin Ottmann, 2017. Profits from Peace: The Political Economy of Power-Sharing and Corruption. World Development Vol. 99, pp. 60-74.

Fred Hitzhusen, Pierre Wilner Jeanty, 2006. Analyzing the Effects of Conflicts on Food Security in Developing Countries: An Instrumental Variable Panel Data Approach. Selected Paper prepared for presentation at the American Agricultural Economics Association Annual Meeting, Long Beach, California.

Goodiel Charles Moshia, Hilda Jacob Mwakatumbula, 2017. Effects of political stability and sector regulations on investmentsin African mobile markets. Telecommunications Policy 41 (2017) 651-661.

Greene, William H. 2008. Econometric Analysis, Sixth Edition. Upper Saddle River, NJ: Prentice Hall.

Hanne Fjelde, 2009. Buying Peace? Oil Wealth, Corruption and Civil War, 1985-99. vol. 46, no. 2, pp. 199-218 Sage Publications (Los Angeles, London, New Delhi, Singapore and Washington DC). 
IEA Report. 2014. International Energy Agency. Annual Report. OECD/IEA.

IEA, 2007. «Energy Security and Climate Policy: Assessing Interactions.” OECD/IEA, Paris, France.

Indur M. Goklany, 2002. The Globalization of Human Well-Being. Policy analysis No. 447.

Issifou, Ismael, 2016. Can migration reduce civil conflicts as an antidote to rent-seeking? Economic Systems - http://dx.doi.org/10.1016/j.ecosys.2016.11.003.

Institute for Economics and Peace, Sydney office, GPI index (2016) http://economicsandpeace.org/.

James D. Fearon and David D. Laitin, 2011. Ethnicity, Insurgency, and Civil War. The American Political Science Review, Vol. 97, No. 1 (Feb., 2003), pp. 75-90.

Jansen, J.C. and A.J. Seebregts. 2010. «Long-term Energy Services Security: What is it and How Can it be Measured and Valued?" Energy Policy 38(4): 1654-1664.

Jean-François Maystadt, Jean-François Trinh Tan, Clemens Breisinger,2014. Does food security matter for transition in Arab countries? Food Policy 46 (2014) 106-11.

Jo Thori Lind and Halvor Mehlum, 2010. With or Without U? The Appropriate Test for a U-Shaped Relationship. Oxford Bulletin of Economics and Statistics, 72, 1, 0305-9049 56(4), 563-595.

Kjetil Bjorvatn and Mohammad Reza Farzanegan, 2015. Resource rents, balance of power, and political stability. Journal of Peace Research 2015, Vol. 52(6) 758-773.

Li Qionga, $\mathrm{Hu}$ Junhuaa, 2015. Military expenditure and unemployment in China1. Procedia Economics and Finance $30-498-504$.

Livia Ilie, 2006. Economic considerations regarding the first oil shock, 1973 - 1974. MPRA Paper No. 6431, posted 22. December 2007 18:35 UTC.

Loschel, A., U. Moslener and D.T.G. Rubbelke, 2010. «Indicators of Energy Security in Industrialized Countries.” Energy Policy 38(4): 1665-1671.

Mădălina Radu, 2015. Political stability - a condition for sustainable growth in Romania? Procedia Economics and Finance 30 - $751-757$.

Maya Jegen, 2014. The European Commission (2001) "Energy policy in the European Union: The power and limits of discourse", Les Cahiers européens de Sciences Po, $\mathrm{n}^{\circ} 02$.

Md Akther Uddin, Md Hakim Ali, Mansur Masih, 2017. Political stability and growth: An application of dynamic GMM and quantile Regression. Economic Modelling 64 - 610-625.

Mehlum, H., Moene, K., Torvik, R., 2006. Institutions and the Resource Curse, The Economic Journal, Vol. 116, Blackwell Publishing Ltd., Oxford.

Michael Borenstein, Larry V. Hedges, Julian P.T. Higgins and Hannah R. Rothstein, 2010. A basic introduction to fixed-effect and random-effects models for meta-analysis. Wiley \& Sons Res. Syn. Meth, 1 97-111.

Mohammad Reza Farzanegan and Stefan Witthuhn, 2014. Demographic transition and political stability: Does corruption matter? Joint Discussion Paper Series in EconomicsNo. 59-2014.

Mohammad Reza Farzanegan, Stefan Witthuhn, 2017. Corruption and Political Stability: Does the Youth Bulge Matter? Marburg Centre for Institutional Economics. Paper Nr. 2016/09. 
Mobarak, A., Karshenasan, A., 2012. The Impact of Institutional Quality on Relation between Resource Abundance and Economic Growth, Iranian Economic Review, Vol.16, No.32, University of Tehran, Tehran.

Nasr G. Elbahnasawy, Michael A. Ellis and Assande de Sire ADOM, 2016. Political Instability and the Informal Economy. World Development Vol. 85, pp. 31-42.

Nyaupane, G. P., Teye, V., \& Paris, C., 2008. Innocents abroad: Attitude change toward hosts. Annals of Tourism Research, 35(3), 650e667.

Ozcan Saritas, Serhat Burmaoglu, 2016. Future of sustainable military operations under emerging energy and security considerations. Technological Forecasting \& Social Change 102 (2016) 331-343. Papers, 50, 563-73.

Papyrakis, E., Gerlagh, R., 2004. The resource curse hypothesis and its transmission channels, Journal of Comparative Economics, Vol. 32, pp. 181-193, Elsevier Science Publishers B.V., North-Holland.

Pendergast, S.M., Clarke, J.A., Van Kooten, G.C., 2008. Corruption and the Curse of Natural Resources, Draft, University of Victoria, Victoria.

Richard Jong-A-Pin, 2009. On the measurement of political instability and its impact on economicgrowth. European Journal of Political Economy 25 - 15-29.

Sarkar, S. K., \& George, B. P., 2010. Peace through alternative tourism: Case studies from Bengal, India. The Journal of Tourism and Peace Research, 1(1).

Scheepers, M. A. Seebregts, J. de Jong, H., Maters, 2007. "EU Standards for Energy Security of Supply - Updates on the Crisis Capability Index and the Supply/Demand Index Quantification for EU27." Energy Research Center of the Netherlands, The Hague.

Schippa C., 2011. The Global Peace Index. In: Go F.M., Govers R. (eds) International Place Branding Yearbook 2011. Palgrave Macmillan, London.

Schneider, F. Bjorvatn, K., Farzanegan M.R., 2012. Resource Curse and Power Balance: Evidence from Oil-Rich Countries. World Development Vol. 40, No. 7, pp. 1308-1316.

Shri Dewi Applanaidua, Nor'Aznin Abu Bakara, Amir Hussin Baharudin, 2014. An Econometric Analysis of Food Security and Related Macroeconomic Variables in Malaysia: A Vector Autoregressive Approach (VAR). UMK Procedia 1- 93 - 102.

The Clingendael International Energy Program, 2004. Annual Report.

The Millennium Development Goals (MDGs), 2015. United Nations Report.

The World Bank, Worldwide Governance Indicators (WGI), 2016. [Data files]. Retrieved from http://info.worldbank.org/governance/wgi/\#home.

The World Bank, Data set, 2016. Atlas method [Data files]. Retrieved from http://data.worldbank.org/indicator.

Toufiq Siddiqi, 2013. Pakistan, India, China, and the United States: Energy, Climate Change, and National Security. Foreign Policy Research Institute.

Ummad Mazhar and Juvaria Jafri, 2017. Can the shadow economy undermine the effect of political stability on inflation? Empirical evidence. Journal of Applied Economics. Volume 20, Pages 395-42.

Usama Al-Mulali, Ilhan Ozturk, 2015. The effect of energy consumption, urbanization, trade openness, industrial output, and the political stability on the environmental degradation in the MENA (Middle East and North African) region. Energy 84-382e389. 
Vijayamohanan Pillai N., 2016. Panel Data Analysis with Stata Part 1 Fixed Effects and Random Effects Models. MPRA Paper No. 76869, posted 20 February 2017 09:51 UTC.

Voxi Amavilah, Simplice A. Asongu, Antonio R. Andrés, 2017. Effects of globalization on peace and stability: Implications for governance and the knowledge economy of African countries. Technological Forecasting \& Social Change 122 - 91-103.Working Paper No. 137.

World News Tomorrow, 2013. https://www.thenational.ae/world/mena/kuwait-gives-each-citizendh13-000-and-free-food-1.382698.

Wu MengYun, Muhammad Imran, Muhammad Zakaria, Zhang Linrong, Muhammad Umer Farooq, Shah Khalid Muhammad, 2018. Impact of terrorism and political instability on equity premium: Evidence from Pakistan. Physica A 492 - 1753-1762. 


\section{Appendix A: Additional Figures and Tables}

Table 7: Detailed Data Description

\begin{tabular}{|c|c|c|c|c|c|c|c|c|}
\hline \multicolumn{2}{|l|}{ Variable } & \multirow{4}{*}{$\frac{\text { Mean }}{2.069827}$} & \multirow{2}{*}{$\frac{\text { std. Dev. }}{.430324}$} & \multirow{2}{*}{$\frac{\text { Min }}{1.089}$} & \multirow{2}{*}{$\frac{\operatorname{Max}}{3.605}$} & \multicolumn{3}{|c|}{ Observations } \\
\hline GPI & overall & & & & & $\mathrm{N}$ & $=$ & 1368 \\
\hline & between & & .4192695 & 1.168444 & 3.427778 & $\mathrm{n}$ & $=$ & 152 \\
\hline & within & & .1020814 & 1.441272 & 2.851383 & $\mathrm{~T}$ & $=$ & 9 \\
\hline \multirow[t]{3}{*}{ Year } & overall & 2012 & 2.582933 & 2008 & 2016 & $\mathrm{~N}$ & $=$ & 1368 \\
\hline & between & & $\mathrm{O}$ & 2012 & 2012 & $\mathrm{n}$ & $=$ & 152 \\
\hline & within & & 2.582933 & 2008 & 2016 & $\mathrm{~T}$ & $=$ & 9 \\
\hline \multirow[t]{3}{*}{ Country } & overall & 76.5 & 43.89372 & 1 & 152 & $\mathrm{~N}$ & $=$ & 1368 \\
\hline & between & & 44.02272 & 1 & 152 & $\mathrm{n}$ & $=$ & 152 \\
\hline & within & & 0 & 76.5 & 76.5 & $\mathrm{~T}$ & $=$ & 9 \\
\hline \multirow[t]{3}{*}{ TNR_lagl } & overall & 9.202687 & 12.22802 & $\mathrm{O}$ & 61.35384 & $\mathrm{~N}$ & $=$ & 1203 \\
\hline & between & & 12.0166 & .0002246 & 53.24468 & $\mathrm{n}$ & $=$ & 152 \\
\hline & within & & 3.540311 & -15.1647 & 31.93566 & $\mathrm{~T}$ & $=$ & 7.91447 \\
\hline \multirow[t]{3}{*}{ FER_lag 1} & overall & 2.892031 & 1.490698 & 1.149 & 7.542 & $\mathrm{~N}$ & $=$ & 1216 \\
\hline & between & & 1.490232 & 1.217375 & 7.4285 & $\mathrm{n}$ & $=$ & 152 \\
\hline & within & & .1190913 & 2.189031 & 3.641031 & $\mathrm{~T}$ & $=$ & 8 \\
\hline \multirow[t]{3}{*}{ Unem_1 1 } & overall & 8.598608 & 6.181387 & .1 & 37.6 & $\mathrm{~N}$ & $=$ & 1358 \\
\hline & between & & 5.594627 & .3947778 & 28.44144 & $\mathrm{n}$ & $=$ & 152 \\
\hline & within & & 2.955395 & -15.98284 & 29.89916 & $\mathrm{~T}-\mathrm{bar}$ & $=$ & 8.93421 \\
\hline \multirow{3}{*}{ Ig_FDI $\sim 1$} & overall & 21.23145 & 2.149484 & 10.9227 & 26.95012 & $\mathrm{~N}$ & $=$ & 1283 \\
\hline & between & & 1.829951 & 15.98771 & 26.33864 & $\mathrm{n}$ & $=$ & 152 \\
\hline & within & & 1.108644 & 12.48325 & 27.83619 & $\mathrm{~T}-\mathrm{bar}$ & $=$ & 8.44079 \\
\hline \multirow[t]{3}{*}{ 1g_tou 1} & overall & 14.41134 & 1.750416 & 9.425451 & 18.25169 & $\mathrm{~N}$ & $=$ & 1159 \\
\hline & between & & 1.739436 & 10.26682 & 18.2076 & $\mathrm{n}$ & $=$ & 147 \\
\hline & within & & .3925182 & 11.76896 & 18.88978 & $\mathrm{~T}-\mathrm{bar}$ & $=$ & 7.88435 \\
\hline \multirow[t]{3}{*}{ GDPPC_ $\sim 1$} & overall & 1.79804 & 4.430891 & -62.22509 & 24.66657 & $\mathrm{~N}$ & $=$ & 1346 \\
\hline & between & & 2.308543 & -12.5371 & 7.719772 & $\mathrm{n}$ & $=$ & 152 \\
\hline & within & & 3.861785 & -47.88994 & 23.21893 & $\mathrm{~T}-\mathrm{bar}$ & $=$ & 8.85526 \\
\hline \multirow[t]{3}{*}{$\mathrm{AR} \_1 \mathrm{an} \sim 1$} & overall & .2511424 & .277539 & .0001024 & 2.134197 & $\mathrm{~N}$ & $=$ & 1061 \\
\hline & between & & .2774263 & .0001169 & 2.044663 & $\mathrm{n}$ & $=$ & 152 \\
\hline & within & & .0174689 & .0607523 & .3422562 & $\mathrm{~T}$ & $=$ & 6.98026 \\
\hline \multirow[t]{3}{*}{ CC_lagl } & overall & -.1030817 & 1.013369 & -1.672876 & 2.446495 & $\mathrm{~N}$ & $=$ & 1366 \\
\hline & between & & .9151476 & -1.492674 & 2.275382 & $\mathrm{n}$ & $=$ & 152 \\
\hline & within & & .4421548 & -3.532347 & 2.799488 & $\mathrm{~T}-\mathrm{bar}$ & $=$ & 8.98684 \\
\hline \multirow[t]{3}{*}{ EI_lag 1} & overall & -20.62331 & 145.2841 & -944.8928 & 98.24676 & $\mathrm{~N}$ & $=$ & 944 \\
\hline & between & & 143.6347 & -701.2417 & 97.77361 & $\mathrm{n}$ & $=$ & 131 \\
\hline & within & & 26.89942 & -264.2744 & 216.0597 & $\mathrm{~T}$ & $=$ & 7.20611 \\
\hline \multirow[t]{3}{*}{ FD_lag 1} & overall & 82.83856 & 95.44572 & $\mathrm{O}$ & 581 & $\mathrm{~N}$ & $=$ & 1307 \\
\hline & between & & 89.17926 & .3333333 & 470.5556 & $\mathrm{n}$ & $=$ & 152 \\
\hline & within & & 40.7951 & -313.717 & 479.9497 & $\mathrm{~T}$-bar & $=$ & 8.59868 \\
\hline \multirow[t]{3}{*}{ FD_sq_ $\sim 1$} & overall & 15965.14 & 35485.65 & $\mathrm{O}$ & 337561 & $\mathrm{~N}$ & $=$ & 1307 \\
\hline & between & & 33906 & .4444444 & 241671 & $\mathrm{n}$ & $=$ & 152 \\
\hline & within & & 16704.45 & -220229.9 & 272145.6 & T-bar & $=$ & 8.59868 \\
\hline \multirow[t]{3}{*}{$R_{\text {_Law_ }} \sim 1$} & overall & -.1155691 & .993998 & -2.178493 & 2.100273 & $\mathrm{~N}$ & $=$ & 1367 \\
\hline & between & & .8996407 & -1.705464 & 1.915605 & $\mathrm{n}$ & $=$ & 152 \\
\hline & within & & .4297385 & -3.285915 & 2.840571 & $\mathrm{~T}$-bar & $=$ & 8.99342 \\
\hline $\mathrm{V} \_\mathrm{ACC}_{-} \sim 1$ & overall & -.1391511 & .9704558 & -2.259159 & 1.737975 & $\mathrm{~N}$ & $=$ & 1367 \\
\hline & between & & .8680537 & -1.999612 & 1.569898 & $\mathrm{n}$ & $=$ & 152 \\
\hline & within & & .4393638 & -3.152859 & 2.722749 & $\mathrm{~T}-\mathrm{bar}$ & $=$ & 8.99342 \\
\hline
\end{tabular}


Table 8: Correlation Matrix of Used Variables

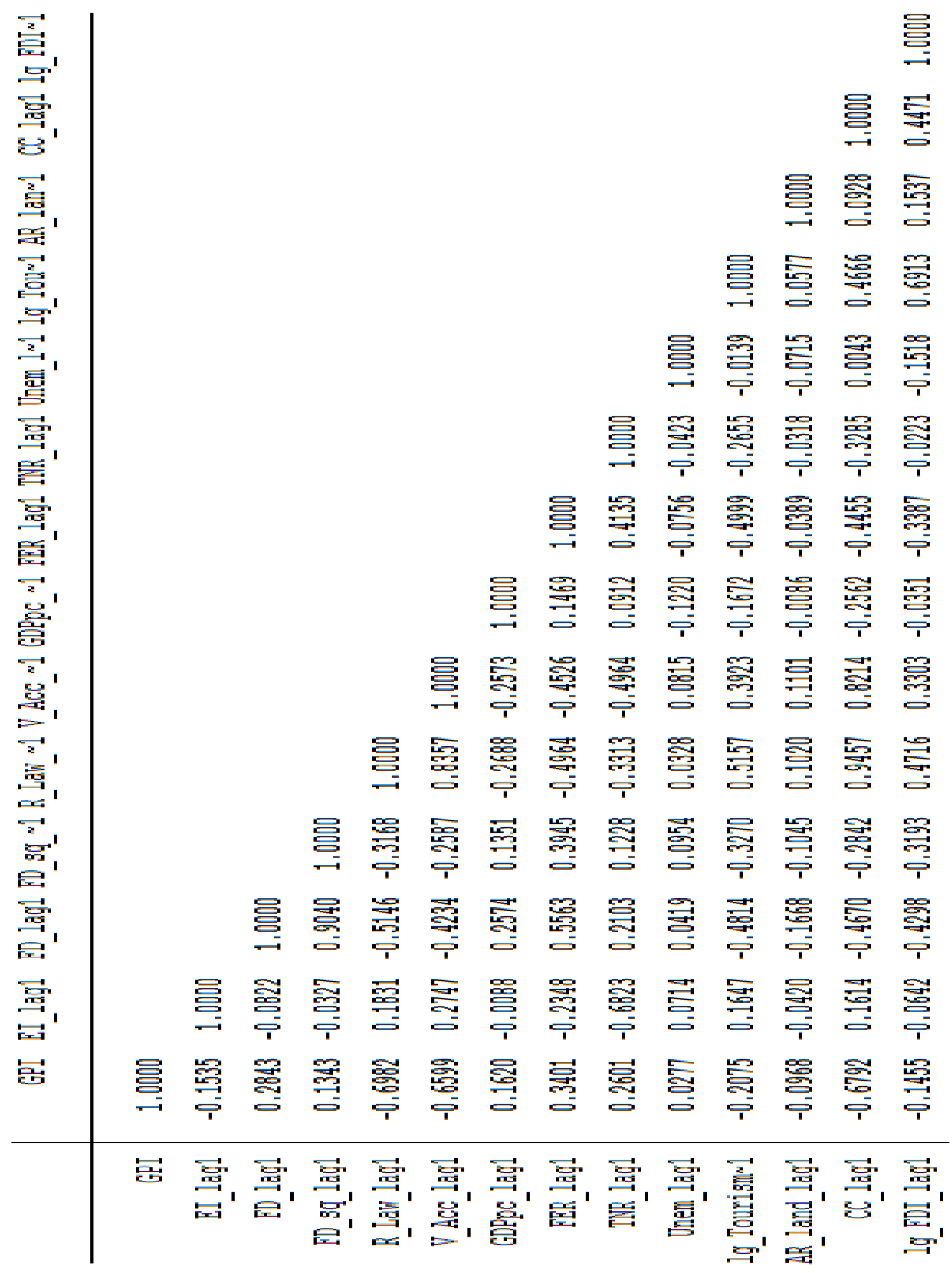

Author's illustrations: STATA Software 
Table 9: GPI index composition

\begin{tabular}{|l|l|}
\cline { 2 - 2 } \multicolumn{1}{l|}{} & Contribution to Overall score \\
\hline Ongoing Domestic and International Conflict & \\
\hline Level of internal conflicts & $3.22581 \%$ \\
\hline Deaths from external conflict & $7.07196 \%$ \\
\hline Deaths from internal conflict & $6.30824 \%$ \\
\hline Level of external conflicts & $3.22581 \%$ \\
\hline Organized internal conflict & $6.30824 \%$ \\
\hline Neighbouring countries relations & $7.07196 \%$ \\
\hline Societal Safety and Security & \\
\hline Perceptions of criminality & $3.78495 \%$ \\
\hline Refugees and IDPs & $5.65757 \%$ \\
\hline Political instability & $5.04659 \%$ \\
\hline Political terror & $5.04659 \%$ \\
\hline Impact of terrorism & $2.52330 \%$ \\
\hline Homicide rate & $5.04659 \%$ \\
\hline Violent crime & $5.04659 \%$ \\
\hline Violent demonstrations & $3.78495 \%$ \\
\hline Incarceration rate & $3.78495 \%$ \\
\hline Security officers and police rate & $3.78495 \%$ \\
\hline Militarisation & $3.78495 \%$ \\
\hline Military expenditure (\% GDP) & $2.82878 \%$ \\
\hline Armed services personnel rate & $2.82878 \%$ \\
\hline Imports of weapons & $2.52330 \%$ \\
\hline Exports of weapons & $4.24318 \%$ \\
\hline UN peacekeeping funding & $2.82878 \%$ \\
\hline Nuclear and Heavy weapons Capabilities & $4.24318 \%$ \\
\hline Access to small arms & \\
\hline
\end{tabular}

Source: Institute for Economics \& Peace 2017 


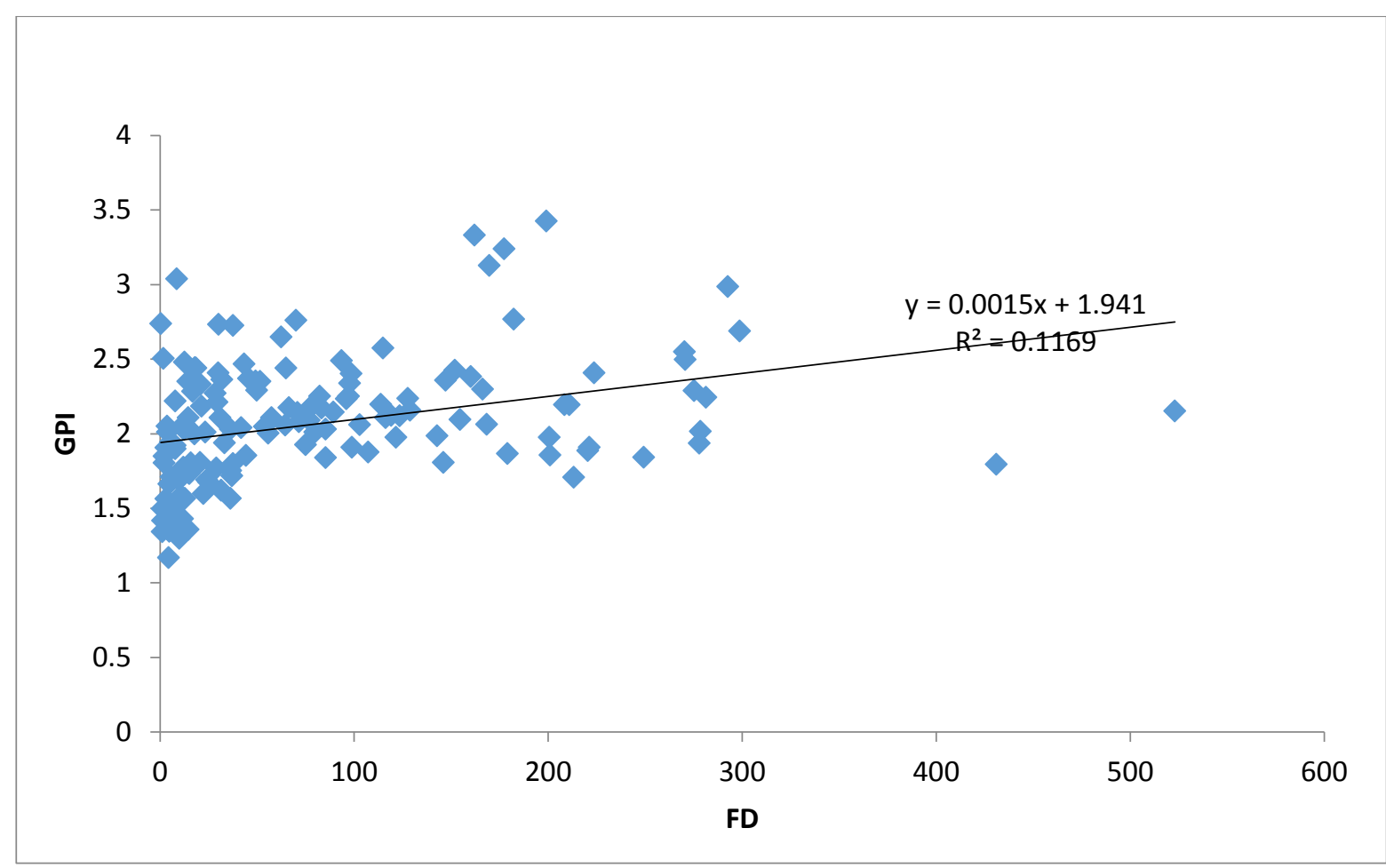

Author's illustrations: STATA Software

Figure 9: Relationship between average FD and GPI index (2008-2016)

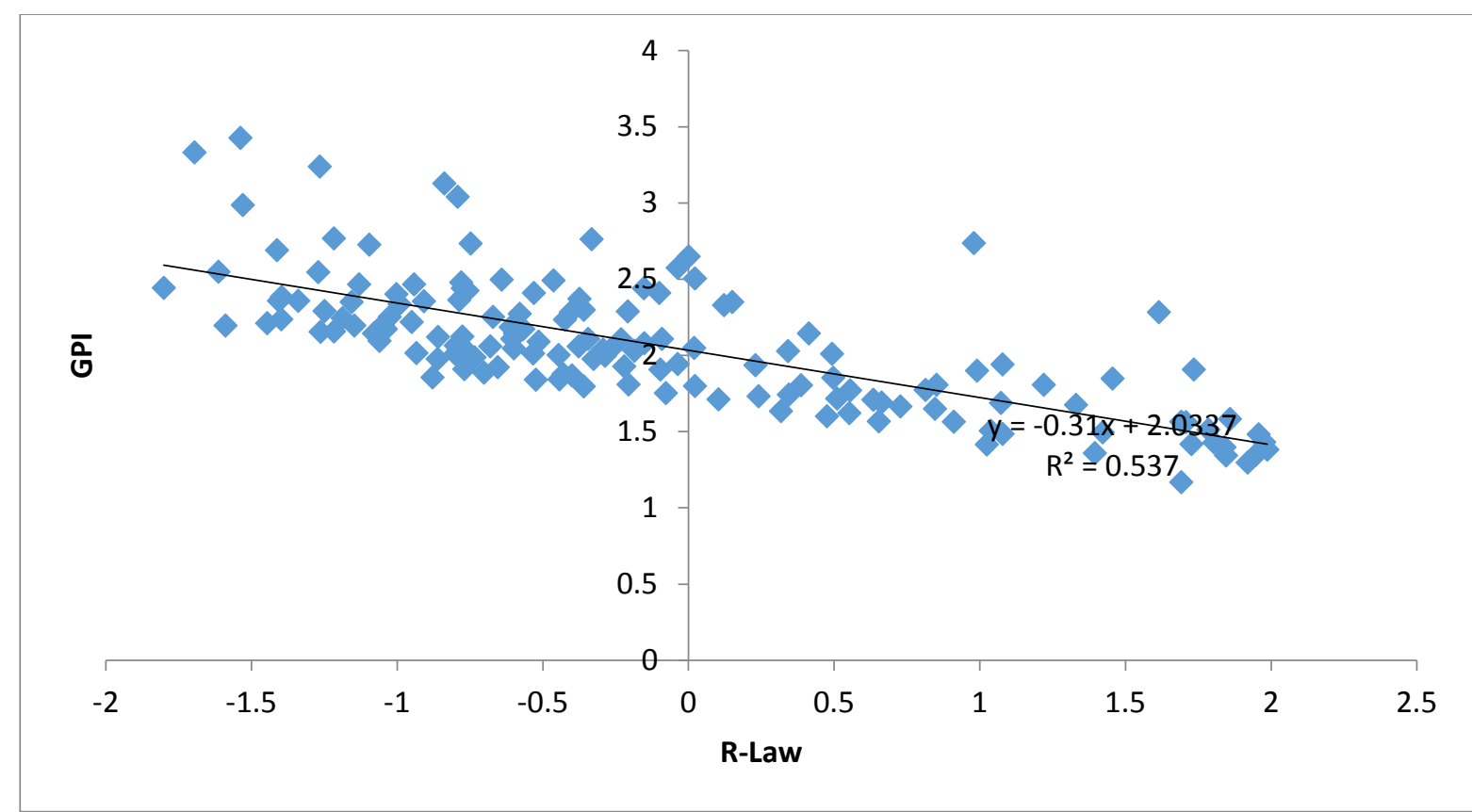

Author's illustrations: STATA Software

Figure 10: relationship between average RL index and GPI (2008-2016) 